\title{
The behaviour of platelets in natural diamonds and the development of a new mantle thermometer
}

\author{
L. Speich ${ }^{1}$ (1) - S. C. Kohn ${ }^{1}$ - G. P. Bulanova ${ }^{1}$ - C. B. Smith ${ }^{1}$
}

Received: 31 July 2017 / Accepted: 3 April 2018 / Published online: 19 April 2018

(c) The Author(s) 2018

\begin{abstract}
Platelets are one of the most common defects occurring in natural diamonds but their behaviour has not previously been well understood. Recent technical advances, and a much improved understanding of the correct interpretation of the main infrared (IR) feature associated with platelets (Speich et al. 2017), facilitated a systematic study of platelets in 40 natural diamonds. Three different types of platelet behaviour were identified here. Regular diamonds show linear correlations between both B-centre concentrations and platelet density and also between platelet size and platelet density. Irregular diamonds display reduced platelet density due to platelet breakdown, anomalously large or small platelets and a larger platelet size distribution. These features are indicative of high mantle storage temperatures. Finally, a previously unreported category of subregular diamonds is defined. These diamonds experienced low mantle residence temperatures and show smaller than expected platelets. Combining the systematic variation in platelet density with temperatures of mantle storage, determined by nitrogen aggregation, we can demonstrate that platelet degradation proceeds at a predictable rate. Thus, in platelet-bearing diamonds where $\mathrm{N}$ aggregation is complete, an estimate of annealing temperature can now be made for the first time.
\end{abstract}

Keywords Diamond · Platelets · Thermochronometry · FTIR

\section{Introduction}

Diamonds are a valuable tool in studying mantle processes. They remain chemically unchanged by their transportation to the surface by kimberlite and lamproite magmas. Thus, the crystallographic defects and inclusions within them reflect their thermal history during growth and mantle storage only. Most diamonds were formed in the lithospheric upper mantle at a depth between 140 and $200 \mathrm{~km}$ (e.g. Stachel and Harris 2008) but diamonds from the sublithospheric upper mantle, the transition zone and lower mantle have been recorded as well (e.g. Harte 2010; Walter et al. 2011), putting diamonds among the deepest sourced samples of mantle material available for study. Additionally, diamonds are

Communicated by Othmar Müntener.

Electronic supplementary material The online version of this article (https://doi.org/10.1007/s00410-018-1463-4) contains supplementary material, which is available to authorized users.

L. Speich

1s13943@my.bristol.ac.uk

1 School of Earth Sciences, University of Bristol, Bristol, UK among the oldest known geological samples and thus present an opportunity to study mantle processes over geologic time scales (for example, see Shirey and Richardson 2011).

Platelets are extended planar defects that occur in diamond containing aggregated forms of nitrogen. They are among the most common defects in natural diamonds and their presence is often reported in FTIR studies of natural diamond (e.g. Bulanova et al. 2018). However, their formation and behaviour at high temperatures are not fully understood and to our knowledge only one attempt has been made to utilise them quantitatively in a geological context (Mendelssohn and Milledge 1995). Thus, the aim of this paper is to understand some of the characteristics of the most prominent platelet IR feature in more detail and to quantify systematic changes making platelets. These efforts will make platelets accessible as a new tool in studying the thermal history of diamonds.

Platelet formation is closely linked to nitrogen aggregation-the process by which nitrogen within the diamond structure undergoes a sequence of defect reactions over time (Allen and Evans 1981). Nitrogen is the most abundant impurity in diamond and is incorporated into the crystal lattice during growth as single atoms substituting for carbon 
(Dyer et al. 1965). This type of defect is called a C-centre. In natural diamond that has been subjected to typical mantle temperatures, $\mathrm{C}$-centres are very rare since nitrogen diffuses to form pairs, the so-called A-centres (Davies 1981), within a few million years under these conditions. Over longer timescales (billions of years) at typical mantle conditions, nitrogen can aggregate further to form B-centres, groups of four nitrogen atoms arranged tetrahedrally around a vacancy (Bursill 1983).

It is widely accepted today that platelets consist of a thin $\{100\}$ layer of carbon interstitials (Humble 1982; Goss et al. 2003). In the past, a number of models involving nitrogen have been discussed and refuted (e.g. Lang 1964). In fact, electron energy loss measurements of the nitrogen content in platelets show a wide range of concentrations between undetectable (Bruley and Brown 1989; Bruley 1992) and up to 0.95 nitrogen atoms per unit cell cross section $a^{2}$ in one sample (Fallon et al. 1995). The latter value is equivalent to $47 \%$ of the atoms in a platelet mono-layer. Kiflawi et al. (1998) report values between 0.65 and 0.93 atoms per $a^{2}$ (equivalent to 32 to $46 \%$ ) that do not change significantly upon treatment at high temperature and pressure but values closer to $10 \%$ seem more common in other studies (Bruley 1992; Berger and Pennycook 1982; Fallon et al. 1995) based on a limited number of samples and platelets analysed.

These results indicate that nitrogen is an impurity in the platelet rather than a fundamental building block. In addition, Woods et al. (1993) detected no shift of the most prominent IR feature caused by platelets (often referred to as $\mathrm{B}^{\prime}$ ) in diamonds with isotopically heavy nitrogen, strengthening the argument against models requiring major amounts of nitrogen. Energetic considerations by Goss et al. (2003) suggest that the nitrogen concentration in platelets is affected by nitrogen solubility and kinetic factors. They predict that platelets annealed at high temperatures for sufficient time periods, such as the 'man-made' platelets in Kiflawi et al. (1998), will contain more nitrogen than their lower temperature counterparts. In addition to nitrogen impurities, Goss et al. (2003) also investigate vacant sites as a possible defect within the platelet.

A comprehensive study by Woods (1986) on the relationship between the $\mathrm{B}^{\prime}$ peak, and nitrogen-related features in IR spectra shows that in the majority of diamonds, there is a positive linear correlation between the integrated $\mathrm{B}^{\prime}$ absorption and absorption due to B-centres. The author concludes that nitrogen aggregation and platelet formation are related. This conclusion is also compatible when mass balance is considered: the formation of B-centres from A-centres requires a lattice vacancy, whereas the formation and growth of platelets requires self-interstitials. Interstitials are atoms inhabiting sites within the crystal lattice that would be unoccupied in a perfect diamond crystal. They can consist of an impurity atom or a species native to the mineral, in this case, carbon. The latter is called self-interstitial. It is also evident that since no nitrogen is released from the point defects in this process, it cannot be an essential constituent of platelets.

The exact mechanism of platelet formation is still unknown. Woods (1986) speculates that during formation of B-centres, interstitials could be released and subsequently form platelets. On the other hand, Goss et al. (2003) argue that, based on ab initio calculations, the energetically most favourable mechanism of platelet growth is by the release of vacancies. These vacancies are likely trapped by A-centres (a pair of nitrogen atoms, $\mathrm{N}_{2}$ ) to form first $V \mathrm{~N}_{2}$ (adding a vacancy, $\mathrm{V}$ to the defect) and then B-centres $\left(V \mathrm{~N}_{4}\right)$ by trapping another A-centre. Despite being conceptually different, both scenarios closely link platelet formation and nitrogen aggregation.

Some diamonds show weaker than expected platelet absorption. This is commonly interpreted as the result of platelet breakdown due to short-lived high temperature events (e.g. Melton et al. 2013; Hunt et al. 2009). Plastic deformation is often mentioned as a potential additional cause for platelet degradation (Woods 1986) but was never studied systematically and its exact role in this process is hence unknown.

The dissociation of platelets leads to the formation of voidites and dislocation loops (Hirsch et al. 1986). The former are octahedral defects bounded by $\{111\}$ planes often found in the vicinity of dislocation loops and sometimes partially degraded platelets (e.g. Hirsch et al. 1986). They are often confined to $\{100\}$ sheets (e.g. Barry et al. 1987) but randomly distributed voidites have been reported as well (e.g. Luyten et al. 1994; Rudloff-Grund et al. 2016). However, it has been suggested that randomly distributed voidites may not be associated with platelet breakdown (Vantendeloo et al. 1990). Sizes between a few nano-metres and up to $200 \mathrm{~nm}$ have been reported with large voidites frequently elongated in $<110>$ (e.g. Kiflawi and Bruley 2000; RudloffGrund et al. 2016; Navon et al. 2017).

Several attempts were made to assess the chemical composition and structure of the interior of voidites. The term 'voidite' was coined because on first inspection, these defects appear empty, whereas more recently they have been referred to as micro- or nano-inclusions since several studies have shown the presence of a nitrogenous phase in this type of defect (e.g. Berger and Pennycook (1982); Bruley and Brown (1989)). This phase might be crystalline at mantle pressure but can escape upon exposure during sample preparation (Rudloff-Grund et al. 2016). Navon et al. (2017) demonstrate the presence of solid molecular $\delta-\mathrm{N}_{2}$ under high pressure in these inclusions using Raman spectroscopy.

It has been tentatively suggested that the source of nitrogen in voidites is nitrogen previously present as impurities in platelets. Kiflawi and Bruley (2000) estimated the nitrogen concentration in voidites produced by annealing regular 
diamonds based on previous experimental work by Evans et al. (1995). Nitrogen concentrations in 'man-made' voidites were found to agree with those of naturally occurring voidites and are also roughly equal to the amount of nitrogen found in platelets. However, large uncertainties were associated with measuring the nitrogen concentration in both platelets and voidites. Navon et al. (2017), however, propose the breakdown of B-centres as a source for the nitrogen in voidites.

The kinetics and exact mechanism of platelet degradation are not well understood. Goss et al. (2003) predicts a stable platelet radius of only a few nano-meters, significantly smaller than commonly observed platelets (see Speich et al. 2017, and references therein). In fact, 'giant platelets' with diameters of up to several micro-meters have been reported (e.g. Woods 1976). This implies that platelets are metastable and exist only because their conversion to perfect dislocation loops is kinetically constrained. However, platelet degradation appears to occur more readily under graphite-stable conditions (Evans et al. 1995). A possible mechanism for platelet degradation involving formation and climb of new dislocations and cancelling out the bounding dislocation of the platelets is discussed in Hirsch et al. (1986).

The platelet IR peak is known to vary in both its shape and exact position. Several efforts have been made to trace these variations in appearance back to physical properties of the defects. As was first discovered by Clackson et al. (1990), IR peak position is a measure of average platelet size. The relationship between these two parameters was re-investigated by Speich et al. (2017), who also confirmed that the integrated intensity of the $\mathrm{B}^{\prime}$ peak is controlled by population density as was previously determined by Sumida and Lang (1988). However, the variation in peak width and symmetry are most likely a consequence of the functional form of the relationship between average platelet radius and peak position (Speich et al. 2017), not linked to variations in platelet morphology or size distribution as was proposed in the past (Sobolev et al. 1969; Kiflawi et al. 1998). These observations are the basis for the interpretation of the data discussed in the current paper.

\section{Samples and methods}

\section{Sample preparation}

A set of 40 plane-parallel plates prepared from natural diamonds from various localities worldwide was selected based on previous FTIR results in an attempt to include a wide range of parageneses (eclogitic, ecl; and peridotitic, per) and thermal histories. Samples originate from Argyle (Western Australia), Diavik (Canada), Murowa and Sese (Zimbabwe) and several Yakutian mines (Aikhal, Mir, Udachnaya and 23rd Party Congress).

The diamonds of octahedral and dodecahedral morphology were polished on two sides to yield thin central planeparallel plates oriented parallel to $\{110\}$. This orientation was shown to be optimal to study growth zoning in diamonds by optical methods (Bulanova et al. 2005).

Cathodoluminescence (CL) images were used to confirm sample orientation and that each plate was polished to include the centre of growth of the diamond, such that, ideally, images of the two sides of the plate are mirror images. These images also record the internal structure of the crystal.

Sample thickness ranges from under 200 to $1800 \mu \mathrm{m}$, meaning that some samples are thicker than the ideal thickness for FTIR absorption spectroscopy proposed by Kohn et al. (2016). Thick samples can complicate FTIR analysis by exacerbating the problem of measuring inhomogeneous sample volumes (Kohn et al. 2016). However, we are able to identify samples where this poses a problem, as is shown here.

\section{FTIR}

For Fourier transform infrared (FTIR) spectroscopy, each sample was mounted on a knife-edge aperture. The plate was placed with the unpolished apexes attached to the aperture to leave almost the entire polished area exposed and available for FTIR analysis. This allows for complete mapping of the internal structure of each sample. High resolution maps were obtained with a Thermo iN10 MX microscope, using a $2 \mathrm{~cm}^{-1}$ spectral resolution and typically a step size of $40 \mu \mathrm{m}$ unless stated otherwise. With the aperture set to a size of 50 by $50 \mu \mathrm{m}$, high-quality spectra can be achieved with 64 scans. The instrument was purged with dry air to reduce the background signal.

\section{Data processing}

The software used to obtain maps only allows for rectangular map areas. Due to the typical shape of each diamond plate and the manner of mounting for FTIR, a rectangular map area will always include non-diamond spectra. To simplify data processing, spectra that were measured on inclusions, or close to or off the edge of the diamond were removed from the dataset by visual inspection. All remaining IR spectra were then processed automatically with a set of Python (version 2.7.6) programs developed in our lab for this purpose. For simultaneous baseline removal and normalization to $1 \mathrm{~cm}$ diamond thickness, spectra were fitted to a normalized spectrum of type IIa diamond allowing for a sloping linear baseline. Both the baseline and type IIa spectrum were then subtracted from the measured spectrum. 
Then, the most prominent H-related feature in diamond spectra, the $3107 \mathrm{~cm}^{-1}$ peak, was examined. For this purpose, a third-order polynomial baseline was fitted to the region between 3200 and $3000 \mathrm{~cm}^{-1}$. The baseline was subtracted and a pseudo-Voigt function with the peak position fixed within close proximity of the known value was fitted to the peak using least-squares optimization. Treating this peak first allows the height of the related $1405 \mathrm{~cm}^{-1}$ peak to be predicted since it was found that it is correlated to the height of the $3107 \mathrm{~cm}^{-1}$ peak by a factor of approximately 0.275 . This aids in fitting the platelet peak because the two overlap strongly (see Speich et al. (2017)). Next, the platelet peak was treated as described in Speich et al. (2017).

Concentrations of the two main nitrogen-containing defects observed in the type of diamond studied here (A- and B-centres) were obtained by fitting linear combinations of the pure endmember spectra of the A-, B- and D-components to the one-phonon region of each measured spectrum using a least-squares routine. As the D-component is related to platelets, it was omitted in spectra that do not show the main platelet peak at ca. $1370 \mathrm{~cm}^{-1}$. For platelet containing spectra, the maximum intensity of the D-component was constrained by $\mu_{B}$, the amount of absorption due to B-centres. For regular diamonds, the intensity of the D-component is expected to be 0.365 times that of the B-component (Woods 1986). Assuming that $D$ decreases as platelets are degraded, this value is the maximum possible amount of $D$ and was used as an upper limit in fitting. Concentrations of A- and B-centres were calculated using the absorption coefficients in Boyd et al. (1994, 1995). Assuming a mantle residence time for each diamond according to locality and paragenesis determined from silicate inclusions, model temperatures were calculated for each point on the map using the kinetic rate equation for the A-B reaction from Taylor et al. (1990) and revised activation energy and pre-exponential factor from Taylor et al. (1996). Mantle residence times used and corresponding references can be found in Table 1 .

Images showing the spatial variation in platelet peak characteristics, nitrogen concentration, aggregation state and model temperature and the integrated intensity of the $3107 \mathrm{~cm}^{-1}$ peak were thus produced for all samples. Using the two-dimensional maps and CL images as a guide, core and rim, and in some cases intermediate, regions within the diamond were identified where applicable.

The data were also used to generate diagrams of the covariation of the position, width and symmetry of the platelet peak along with regularity diagrams after Woods (1986), with core and rim regions treated separately. Because of the large number of spectra in each map, a Gaussian kernel density estimation (KDE) was performed on these diagrams using a Gaussian KDE routine implemented into Python (for further information see Scott 2015). Thus, representative values of $\mu_{B}$, platelet peak position, area, width and
Table 1 Mantle storage durations used to obtain model temperatures

\begin{tabular}{lllll}
\hline Locality & Paragenesis & $\begin{array}{l}\text { Crystal- } \\
\text { lization age } \\
(\mathrm{Ga})\end{array}$ & $\begin{array}{l}\text { Eruption } \\
\text { age }(\mathrm{Ga})\end{array}$ & $\begin{array}{l}\text { Mantle stor- } \\
\text { age duration } \\
(\mathrm{Ga})\end{array}$ \\
\hline Argyle & ecl & $1.58^{\mathrm{a}}$ & $1.18^{\mathrm{b}}$ & 0.40 \\
& per & $2.2-3.1^{\mathrm{c}}$ & $1.18^{\mathrm{b}}$ & 1 \\
Diavik & ecl & $1.86^{\mathrm{d}}$ & $0.06^{\mathrm{e}}$ & 1.81 \\
& per & $3.3^{\mathrm{d}}$ & $0.06^{\mathrm{e}}$ & 3.25 \\
Murowa/Sese & ecl/per & $3.4^{\mathrm{f}}$ & $0.54^{\mathrm{g}}$ & 2.9 \\
Yakutia & ecl/per & 3.1 to $3.5^{\mathrm{h}}$ & $0.36^{\mathrm{i}}$ & 2.9 \\
\hline
\end{tabular}

References ${ }^{\mathrm{a}}$ Richardson (1986), ${ }^{\mathrm{b}}$ Pidgeon et al. (1989), ${ }^{\mathrm{c}}$ Luguet et al. (2009), ${ }^{\mathrm{d}}$ Aulbach et al. (2009), ${ }^{\mathrm{e}} \mathrm{Graham}$ et al. (1999), ${ }^{\mathrm{f}}$ Smith et al. (2009), ${ }^{g}$ Smith et al. (2004), ${ }^{\text {h}}$ Pearson et al. (1999), ${ }^{\mathrm{i}}$ Kinny et al. (1997).The effect of a given error in storage duration on calculated temperatures depends on overall storage duration and is more significant for shorter mantle storage durations. For long storage durations $>1 \mathrm{Ga}$, even a large variation in storage duration of several hundred Ma will result in insignificant differences in storage temperatures (Taylor et al. 1990)

symmetry were identified for each zone. These values are akin but not identical to averages of the same parameters. A disadvantage of using averages is that they might not represent real values occurring anywhere in the sample, especially if core and rim data were not separated appropriately. The points obtained by kernel density estimation, in contrast, are representative since they indicate where most of the data in a given dataset fall.

Assessing uncertainties associated with IR spectroscopy of diamond is not simple. Estimates of the uncertainties involved in measuring the size, shape and position of the platelet peak are discussed in Speich et al. (2017). Accurate determination of nitrogen concentrations, and hence mantle storage temperatures, depends on a variety of factors, some of which are different for each spectrum (Kohn et al. 2016). For example, appropriate baseline correction and a high signal-to-noise ratio are essential in improving precision. In samples with low nitrogen concentration (below ca. $80-100 \mathrm{ppm}$ ), uncertainty is larger. The same applies to low concentrations of either B- or A-centres, even if total nitrogen concentration is sufficiently high (i.e. very strong or weak aggregation). In these cases, spectral deconvolution is less straightforward. In favourable cases, nitrogen aggregation model temperatures vary by $\pm 5{ }^{\circ} \mathrm{C}$ or less within a single growth zone even if the variation in nitrogen concentration and aggregation state is large. However, in a worstcase scenario of a highly aggregated (>95\% B) diamond with a short mantle residence time, uncertainty is likely to be on the order of $\pm 50^{\circ} \mathrm{C}$.

Sources of systematic errors in temperature calculation arise from the determination of absorption coefficients for A- and B-centres (standard deviations of $\pm 6 \%$ and $\pm 10 \%$, respectively are reported in Boyd et al. 1994, 1995), and the 
calibration of the nitrogen aggregation thermometer Taylor et al. (1990, 1996).

It should be noted that to calculate the model temperatures provided throughout this paper, a single mantle storage duration was used for the whole diamond unless stated otherwise. Of course, this assumption is not correct since, provided that the diamond grew from the core outward, it follows that the rim must always be younger than the core. Some samples show evidence of two or more phases of growth that may be separated by a period of time with very little or no growth or even dissolution, such as distinctly different isotopic compositions (e.g. Smart et al. 2011). In these cases, the rim could be considerably younger meaning that the model temperature using the same age as for the core would be an underestimate. In fact, Rudnick et al. (1993) and Wiggers de Vries et al. (2013b) report different inclusion ages for core and rim zones in some Yakutian diamonds and the Kohn et al. (2016) model demonstrates that rim growth may have occurred hundreds of million years after core growth.

Another important assumption made here is that the same storage duration can be applied to all diamonds of a certain paragenesis from one locality. Overall, the lack of more detailed inclusion dates adds systematic uncertainty to model temperatures determined from nitrogen aggregation and limits the calibration of a platelet thermometer to a certain extent. However, the effect of a given error in mantle storage duration on calculated nitrogen aggregation model temperatures depends on the overall storage duration. It is more significant for short storage durations and decreases dramatically for storage durations longer than ca. $1 \mathrm{Ga}$ (Taylor et al. 1990). Further, comprehensive inclusion dating, ideally of multiple inclusions within separate growth zones in a single diamond, combined with IR analysis is needed to overcome these difficulties.

\section{Results and discussion}

To explore the spatial distribution of nitrogen and the variation of platelet peak properties across samples, two-dimensional maps were produced. Figure 1 shows examples of a CL image and IR maps of the total nitrogen concentration, aggregation state and model temperature and platelet characteristics of sample DVK 160. All remaining high-resolution maps can be found in Online Resource 1. From these maps, growth zones within the diamond were identified where applicable.

In the case of sample DVK 160, the core is high in nitrogen (in excess of $1200 \mathrm{ppm}$ total nitrogen) and highly aggregated (ca. $85 \%$ ), producing large platelet peaks as a consequence. The rim however, displays lower nitrogen concentration overall, a higher proportion of which is found in
A-centres, leading to much smaller platelet peak areas. A thin zone of high $N_{3} \mathrm{VH}$ abundance can be found near the transition between core and rim as is often reported (Kohn et al. 2016). $N_{3} V H$ is a defect consisting of three nitrogen atoms surrounding a vacancy that has trapped a hydrogen atom and is the cause of the $3107 \mathrm{~cm}^{-1}$ peak. Model temperatures of ca. 1160 and $1090{ }^{\circ} \mathrm{C}$ were obtained for core and rim, respectively. Seemingly higher model temperatures near the core-rim boundary are likely to be an artefact due to analysis of overlapping zones as described in Kohn et al. (2016). Platelet peak position and width show a less clear core-rim division but both vary considerably, especially within the rim area.

Most diamonds show two or more distinct growth zones like DVK 160, characterised by changes in nitrogen concentration, model temperature or platelet behaviour. This observation is in accordance with previous studies suggesting multiple growth events for a single diamond (e.g. Wiggers de Vries et al. 2013a, b). The changes in nitrogen aggregation systematics can occur gradually over hundreds of micro-meters of diamond growth or more commonly within the limit of spatial resolution in FTIR. Other diamonds show multiple narrow, oscillatory growth zones. The origin of such zonation in diamonds is discussed and changes in the composition or oxidation state of the source fluid have been proposed (Wiggers de Vries et al. 2013a, b).

\section{Describing platelet behaviour}

Two approaches were tested to define regular platelet behaviour. The first approach involves using a single, regular representative sample (Mur 235) as a reference (see Fig. 2 for 2-dimensional maps and Fig. 3 top for platelet behaviour). This sample was chosen above others because of its nitrogen aggregation characteristics. Its total nitrogen concentration is well above $100 \mathrm{ppm}$ in all spectra, aggregation ranges from ca. $65 \% \mathrm{~B}\left(\left[N_{\mathrm{B}}\right] /\left[N_{\{\text {total }\}}\right]\right)$ in the core to $35 \% \mathrm{~B}$ in the rim in agreement with total nitrogen concentration, yielding a model temperature of $1135 \pm 2{ }^{\circ} \mathrm{C}$, illustrating the very high precision of the nitrogen aggregation thermometer. Low nitrogen concentrations and both very high and low aggregation can affect data processing adversely, making this sample an ideal candidate. Furthermore, it exhibits a comparatively simple zoning pattern (see Fig. 2), simplifying interpretation of the high resolution map. The second approach uses representative values of all regular samples as determined by KDE as described in section (Fig. 3 bottom).

Four types of diagrams were found to be critical in studying the co-variation of different diamond IR characteristics. These are shown in Fig. 3 and are referred to as diagrams one to four throughout this paper.

Diagram One (see Fig. 3a, e) The first diagram of integrated platelet peak intensity $\left(I\left(B^{\prime}\right)\right)$ versus absorption due to 
Fig. 1 Example of CL image (a) and high resolution IR maps (b-h). Peridotitic sample Diavik 160. b Total nitrogen concentration (ppm), c aggregation state $(\% \mathrm{~B})$, d model temperature derived from nitrogen aggregation $\left({ }^{\circ} \mathrm{C}\right)$, e platelet peak area $\left(\mathrm{cm}^{-2}\right)$, f platelet peak position $\left(\mathrm{cm}^{-1}\right)$, $\mathbf{g}$ width of the platelet peak (FWHM, $\mathrm{cm}^{-1}$ ), h integrated area of the $3107 \mathrm{~cm}^{-1}$ peak $\left(\mathrm{cm}^{-1}\right)$
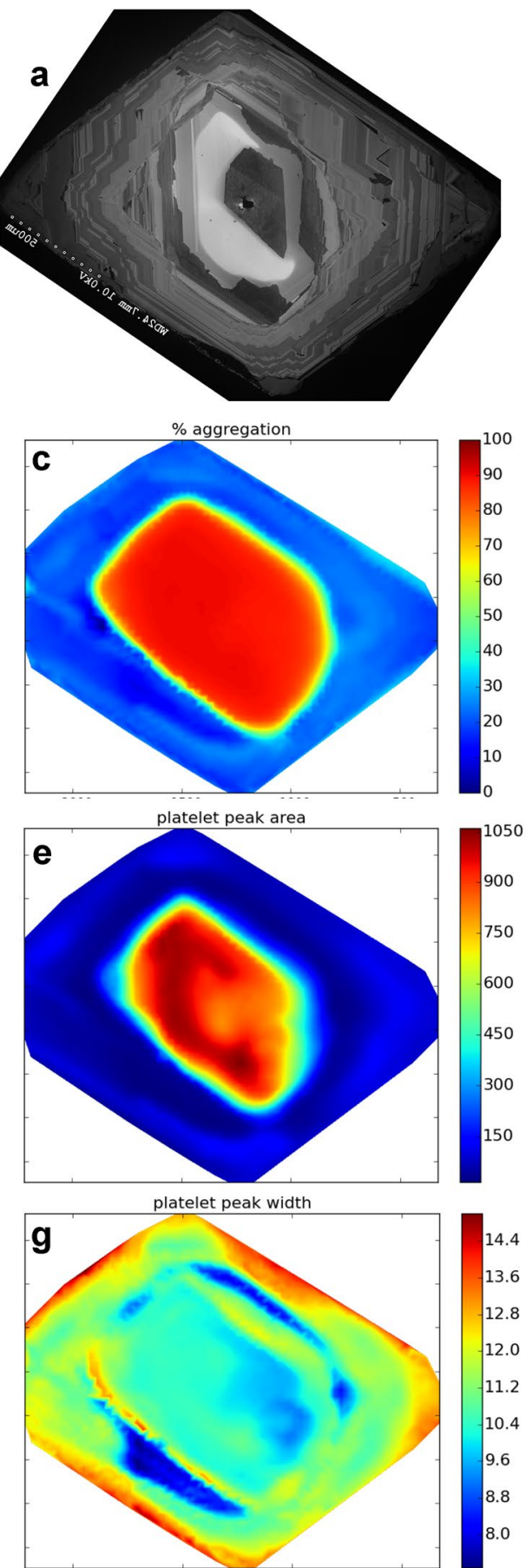
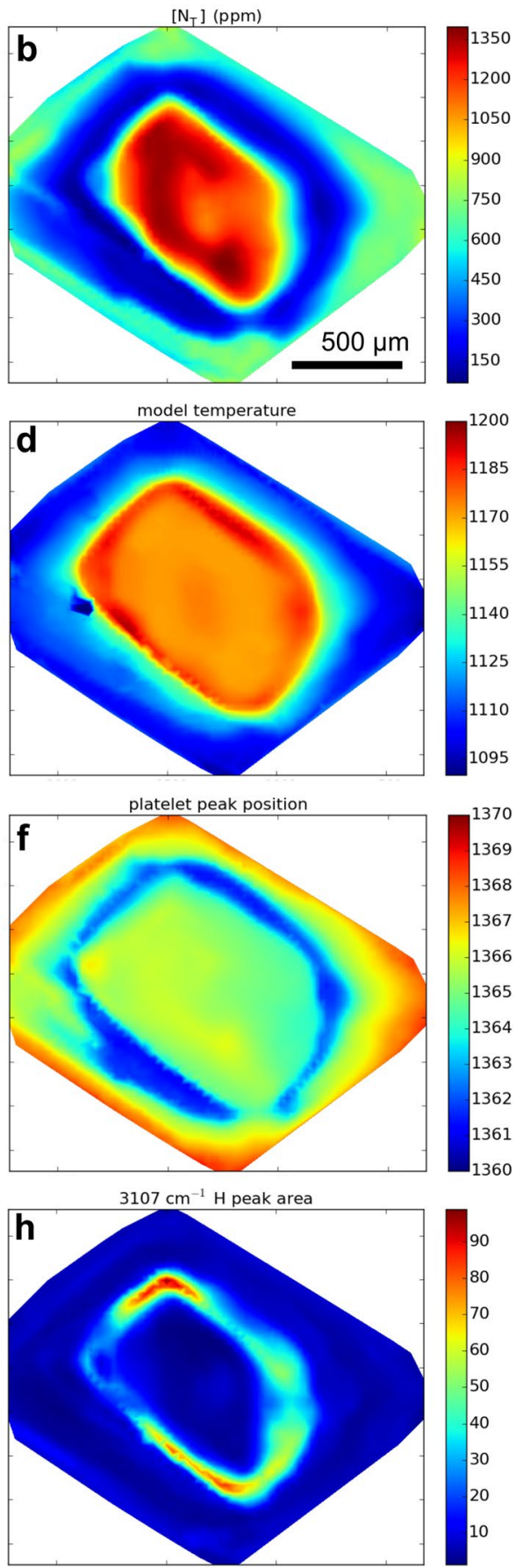

B-centres $\left(\mu_{B}\right)$ was first used by Woods (1986) to distinguish between regular and irregular diamonds. It should be noted that this diagram was modified here to account for differences in the calculation of $I\left(B^{\prime}\right)$, most importantly differences in baseline correction. This was accomplished by locating regular diamonds in the dataset and carrying out a linear regression on values determined by KDE (see Fig. 3e), yielding

$I\left(B^{\prime}\right)=64 \times \mu_{B} \quad\left(R^{2}=0.996\right)$.
It is unclear why some regular diamonds, such as Mur 235 deviate from this line, displaying slightly smaller peak areas. Our reference sample, Mur 235, seemingly defines a lower boundary and follows

$I\left(B^{\prime}\right)=60.9 \times \mu_{B} \quad\left(R^{2}=0.995\right)$

(see Fig. 3a). Other samples fall between these two lines. There appears to be no systematic correlation with model temperature or data quality. The two correlation factors of 
Fig. 2 Example of CL image (a) and high resolution IR maps (b-h). Sample Murowa 235 (per). b Total nitrogen concentration (ppm), $\mathbf{c}$ aggregation state $(\% \mathrm{~B}), \mathbf{d}$ model temperature derived from nitrogen aggregation $\left({ }^{\circ} \mathrm{C}\right)$, e platelet peak area $\left(\mathrm{cm}^{-2}\right)$, f platelet peak position $\left(\mathrm{cm}^{-1}\right)$, $\mathbf{g}$ width of the platelet peak (FWHM, $\left.\mathrm{cm}^{-1}\right), \mathbf{h}$ integrated area of the $3107 \mathrm{~cm}^{-1}$ peak $\left(\mathrm{cm}^{-1}\right)$
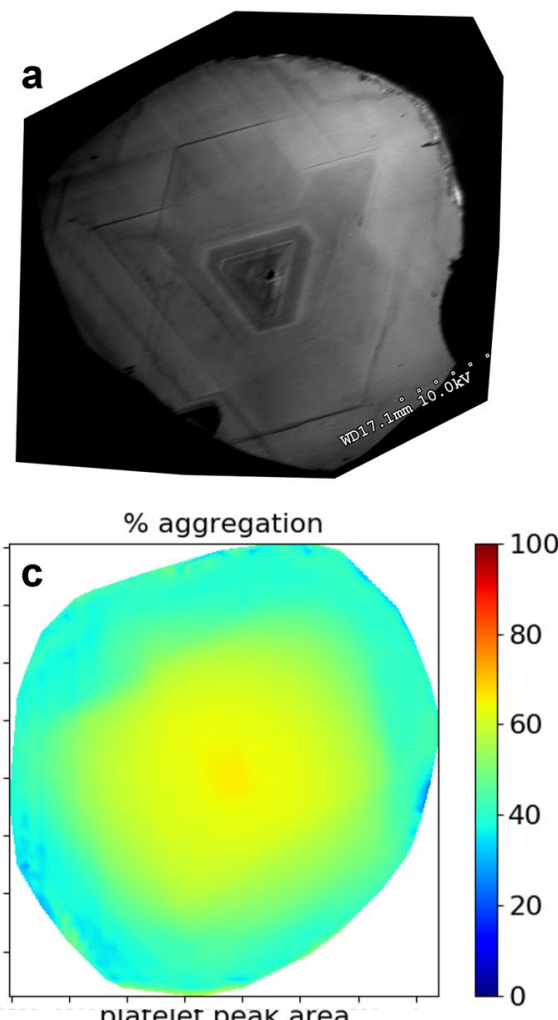

platelet peak area
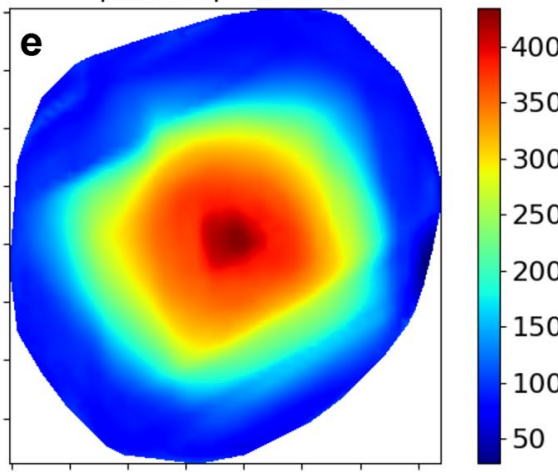

$-350$

$-300$

$-250$

$-200$

$-150$

$-100$

50

platelet peak width

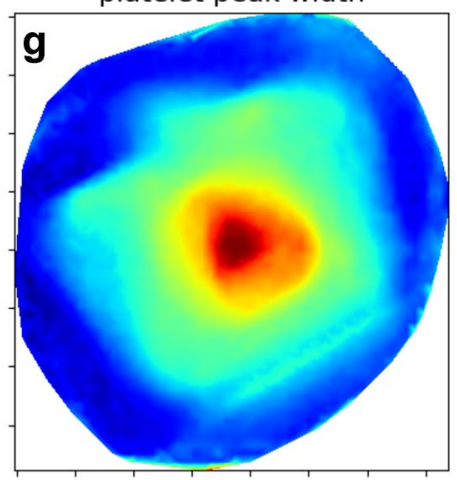

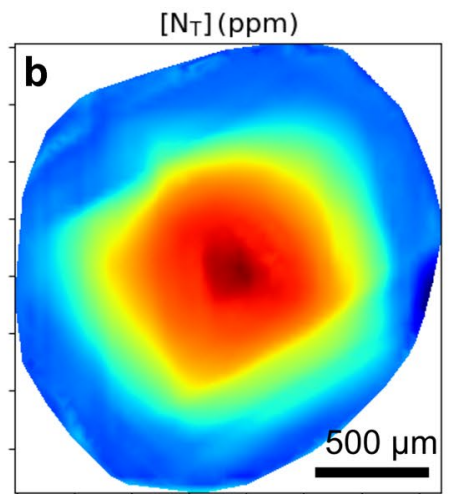

800

700

600

500

$-400$

300

200

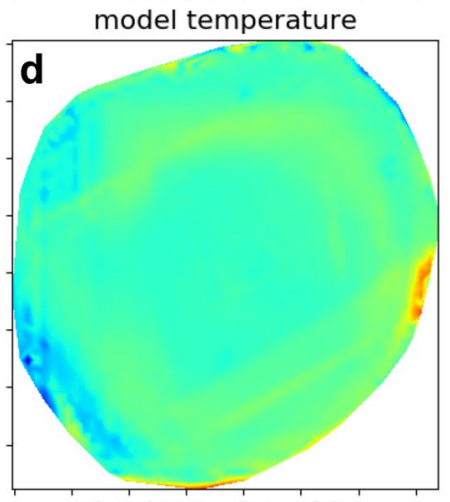

1150

$-1145$

$-1140$

1135

1130

1125

platelet peak position

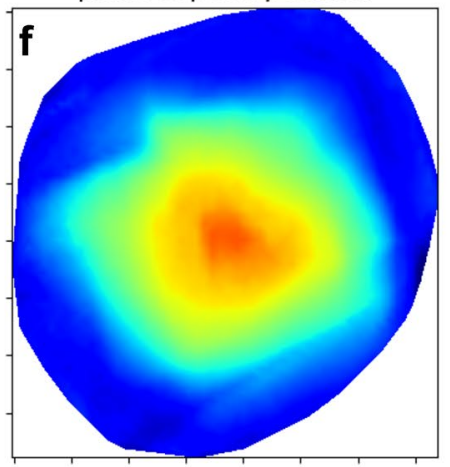

1365.0

1364.5

1364.0

1363.5

1363.0

1362.5

1362.0

1361.5

$3107 \mathrm{~cm}^{-1} \mathrm{H}$ peak area
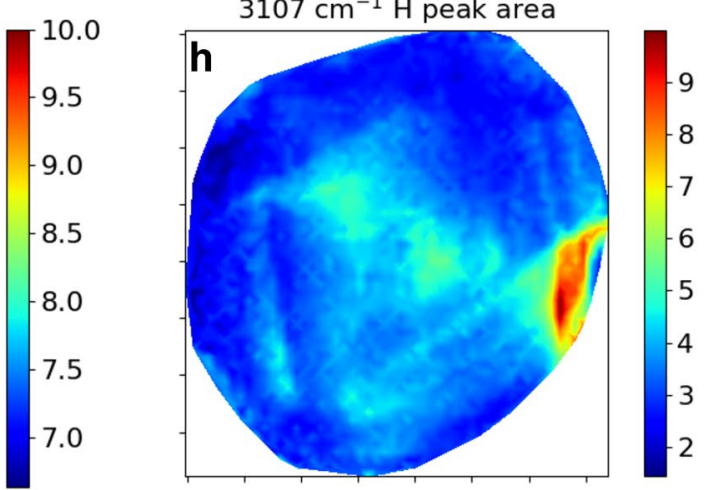

64 and 60.9 stated above are higher than the factor of ca. 50 observed by Woods (1986). The author does not give a detailed description of the baseline correction applied to his data but differences between his approach and ours are the most likely cause for the discrepancy in correlation factors.
Diagram Two (see Fig. 3b, f) The second diagram shows the relationship between $I\left(B^{\prime}\right)$ and the position of the platelet peak maximum. The relationship between these two parameters was found to be more complex than is the case for diagram one. A considerable amount of variation was found 

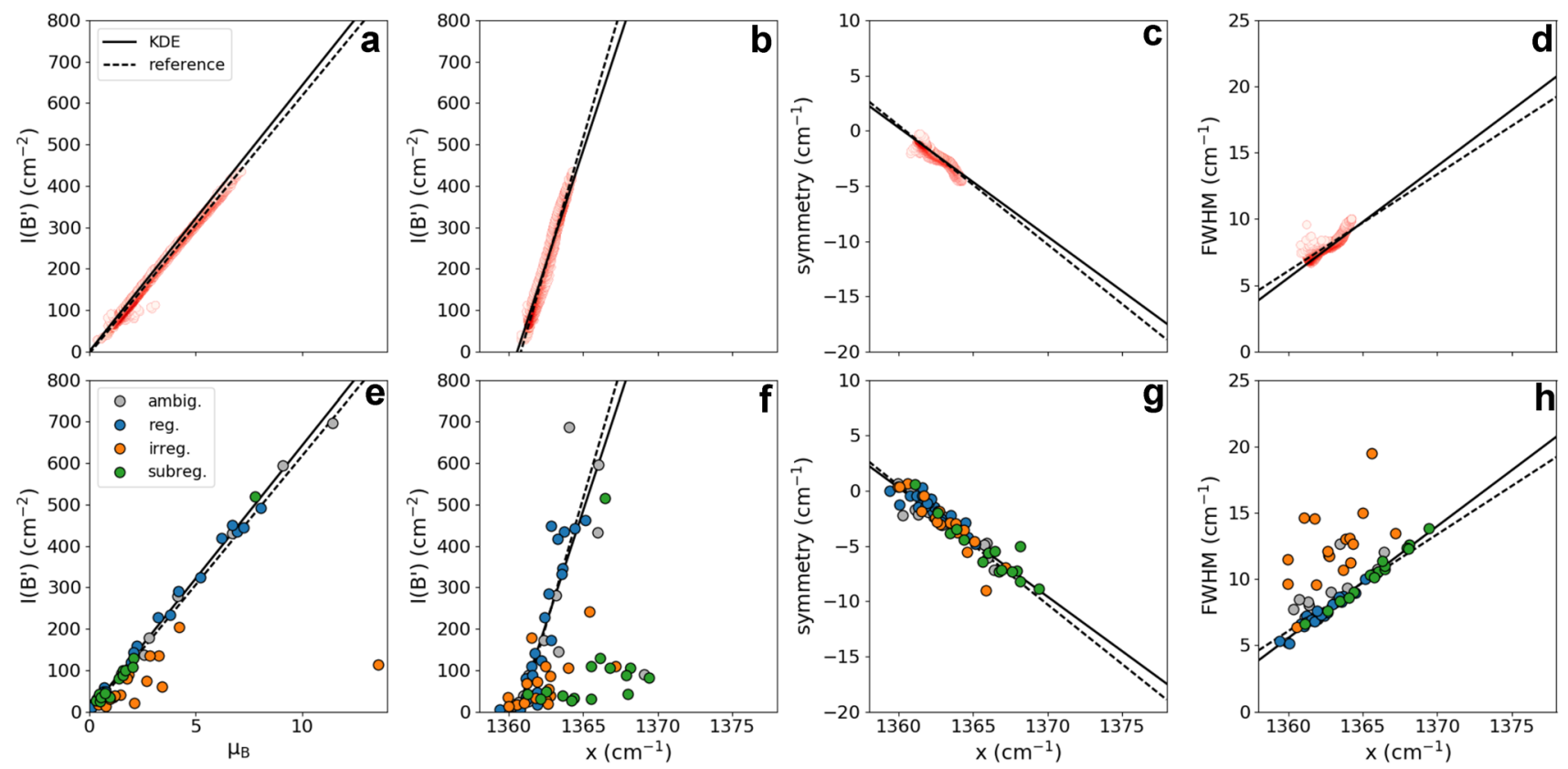

Fig. 3 Diagrams used to distinguish between regular (reg.), irregular (irreg.) and subregular (subreg.) platelet behaviour, comparing two approaches. a-d: Using regular reference sample (Mur 235, see also Fig. 2) e-g: using representative values for all samples determined by kernel density estimation (KDE) to define regular behaviour. A small number of samples could not be assigned to any of these categories unambiguously (ambig.). a and e: regularity diagram after

Woods (1986) (diagram one), b and f: variation of platelet peak area $\left(I\left(B^{\prime}\right)\right)$ with position of the peak maximum $(x)$ (diagram two), $\mathrm{c}$ and $\mathrm{g}$ : variation of peak symmetry with peak position (diagram three), $d$ and h: variation of peak width (FWHM) with position (diagram four). Dashed line: best fit to reference sample (Mur 235), solid line: best fit to values determined by KDE

between samples deemed regular, making an approach of using kernel density estimation somewhat unreliable.

Thus, the relationship between the integrated area $\left(I\left(B^{\prime}\right)\right.$, in $\mathrm{cm}^{-2}$ ) and the position of the maximum of the platelet peak $\left(x\right.$, in $\left.\mathrm{cm}^{-1}\right)$ in our reference sample can be described in terms of the following equation.

$I\left(B^{\prime}\right)=123.3 \times x-1678 \times 10^{2} \quad\left(R^{2}=0.979\right)$

Using representative values for all regular samples as determined by kernel density estimation, yields a very similar relationship, providing some confirmation. However, the variation between samples leads to a certain amount of scatter (see also Fig. 3f).

$I\left(B^{\prime}\right)=109.6 \times x-1492 \times 10^{2} \quad\left(R^{2}=0.731\right)$

Hence, we prefer Eq. 3 using a reference sample even though combining all regular samples may seem more rigorous.

Diagram Three (see Fig. 3c, g) The next diagram examines the variation of platelet peak symmetry with peak position. Peak symmetry is determined as the difference between the average and mode of the distribution of intensities in the platelet peak. Negative values describe peaks skewed towards the high wavenumber side. Platelet behaviour in this diagram can be described with the following equations using $\operatorname{sym}=-1.078 \times x+1467 \quad\left(R^{2}=0.932\right)$

sym $=-0.987 \times x+1342 \quad\left(R^{2}=0.870\right)$

There appears to be very little variation between different diamonds. In other words, peak symmetry behaves in the same fashion regardless of provenance of the diamond, model temperature or total nitrogen concentration. Variations in platelet peak symmetry have been reported previously (e.g. Woods 1986) but were limited to qualitative observations. Our quantitative approach lends further evidence to the conclusion drawn by Speich et al. (2017) that peak symmetry correlates with platelet peak position and hence platelet size.

Diagram Four (see Fig. 3d, h) Finally, a linear trend in platelet peak width (FWHM, in $\mathrm{cm}^{-1}$ ) versus peak position $\left(x\right.$, in $\left.\mathrm{cm}^{-1}\right)$ was found in all subregular and regular diamonds (see Fig. 3d, h). The following equations can be derived, using our reference sample, Mur 235 (Eq. 7) and representative values for all samples (Eq. 8).

$\begin{array}{ll}\text { FWHM }=0.730 \times x-986 & \left(R^{2}=0.844\right) \\ \text { FWHM }=0.844 \times x-1142 & \left(R^{2}=0.984\right)\end{array}$ 
These agree well with peak widths predicted by modelling by Speich et al. (2017) and a similar correlation was found by Woods (1986) (see Fig. 4). Linear regression of data in the latter yields $\mathrm{FWHM}=0.9899 \times x-1339\left(R^{2}=0.839\right)$. As can be seen by comparing the current data and models with the data by Woods (1986) in Fig. 4, considerably wider peaks were observed by Woods (1986). This difference is particularly pronounced in peaks occurring at high wavenumbers with a ca. $4 \mathrm{~cm}^{-1}$ difference in width at $1375 \mathrm{~cm}^{-1}$ and negligible at low wavenumbers. This likely reflects differences in baseline correction but the exact procedure used by Woods (1986) is unclear. Peaks occurring at high wavenumbers are usually large, broad and asymmetric, as is implied by the behaviour found in diagram two-four, and likely show a stronger overlap with the neighbouring 1405 and $1332 \mathrm{~cm}^{-1}$ peaks. Ignoring this overlap results in an inaccurate baseline correction and a large uncertainty in peak height and full width at half maximum, especially for peaks at the high wavenumber end of the observed range.

The systematic variation in all samples confirms the conclusion drawn by Speich et al. (2017) based on modelling that platelet peak width is proportional to platelet peak position which is a proxy for platelet size.

However, the highest temperature irregular diamonds display wider platelet peaks overall (see Fig. $3 \mathrm{~h}$ ) producing a trend that is parallel to that of lower temperature samples but shifted towards broader peaks. The same behaviour has previously been reported for HPHT treated diamonds (Fisher 2009; Kiflawi et al. 1998). There must be an additional unknown factor causing broadening of the $\mathrm{B}^{\prime}$ peak in these samples, such as an unusually wide size distribution. The

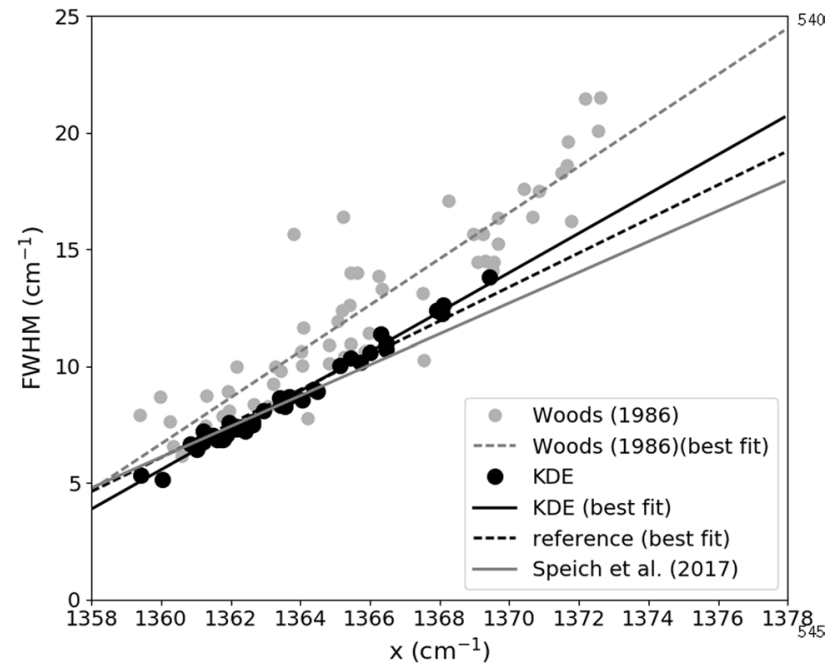

Fig. 4 Comparison of different methods to predict the width (FWHM) of the platelet peak, including data and best fit shown in Fig. 3, using both KDE (regular and subregular only) and reference sample Mur 235, modelling by Speich et al. (2017) and data taken from Woods (1986) and linear regression of the latter fact that this phenomenon only occurs after HPHT treatment and in our irregular diamonds suggests that it is a characteristic of all high temperature stones.

\section{Types of platelet behaviour}

According to the diagrams described shown in Fig. 3, our samples can be roughly divided into three subsets with different platelet characteristics as discussed below. These subsets also correlate with ranges of model temperature derived from nitrogen aggregation thermochronometry $\left(T_{N}\right)$. The three types of platelet behaviour are summarised in Table 2 and representative examples of each type of behaviour are shown in Figs. 5, 6 and 7. The full dataset including nitrogen aggregation temperatures and information on the paragenesis of each diamond can be found in Online Resource 2.

Regular diamonds (see Fig. 5) were first defined by Woods (1986) as displaying a linear relationship between platelet peak area and B-centre absorption (our diagram one). In addition, diamonds in this group also show a linear variation of platelet peak area $\left(I\left(B^{\prime}\right)\right.$, in $\left.\mathrm{cm}^{-2}\right)$ with peak position $\left(x\right.$, in $\left.\mathrm{cm}^{-1}\right)$, roughly resembling Eq. 3 (our diagram two).

Since platelet peak area is related to platelet density and peak position is linked to platelet diameter (using equations and correlation factors from Speich et al. 2017), it follows that the platelet diameter $(D$, in $\mathrm{nm})$ and density of the platelets (platelet area per unit volume of diamonds, $\rho_{p}$, in $\mathrm{nm}^{2} / \mathrm{nm}^{3}$ ) are correlated by the following relationship

$\rho_{p}=2.41 \times 10^{-6} \times \frac{2.72 \times 10^{4}}{D}-1.66 \times 10^{5}$

In other words, platelet density is proportional to $1 / D$. This can be explained in terms of classic nucleation and growth theory. If total nitrogen concentration in the diamond is high, a large number of carbon interstitials becomes available as nitrogen aggregates. Thus, oversaturation is high, so that the nucleation rate exceeds the growth of existing platelets. This results in a large number of small platelets. On the other hand, if comparatively few interstitials are available and oversaturation is low, the platelet population will consist of only a few large platelets. However, this seems implausible if platelets grow by releasing vacancies that are subsequently incorporated into B-centres as proposed by Goss et al. (2003). Regular diamonds generally have model temperatures between ca. 1120 and $1220{ }^{\circ} \mathrm{C}$.

Irregular diamonds (see Fig. 6) fall below the line in diagram one and frequently their platelet peaks are at higher or lower wavenumbers than expected for a regular diamond of similar platelet density in diagram two (see Fig. $6 \mathrm{c}$, h and $\mathrm{m})$. However, initial platelet density has to be taken into account and can be inferred from the relationship in diagram one and Eq. 1. When compared to the peak position 

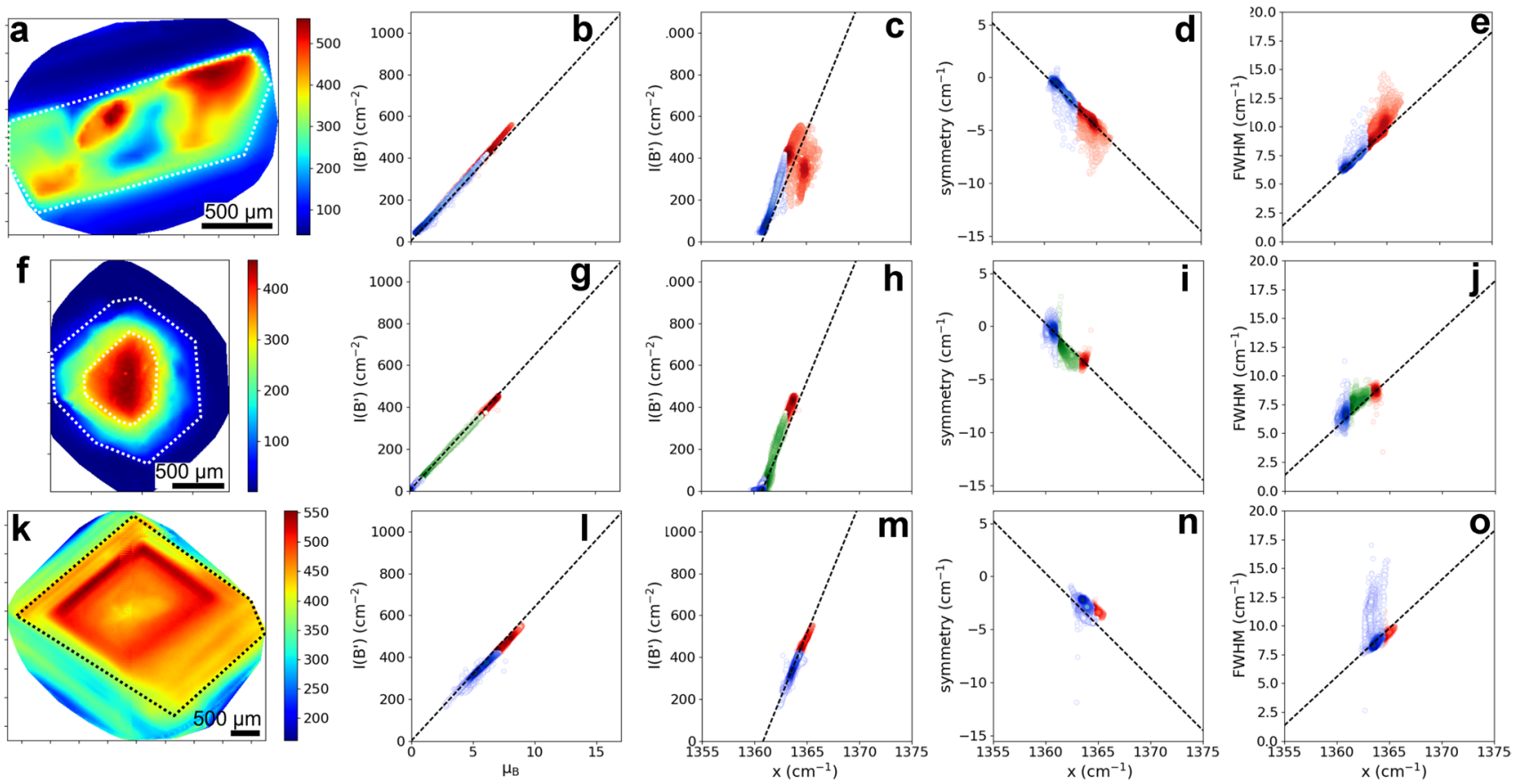

Fig. 5 Examples of regular platelet behaviour. Top: Murowa 141 $\left(T_{N}\right.$ core: $1145^{\circ} \mathrm{C}$, rim: $1135^{\circ} \mathrm{C}$, centre: Aikhal 2100 (per; $T_{N}$ core: $1150^{\circ} \mathrm{C}$, intermediate: $1150{ }^{\circ} \mathrm{C}$, rim: $1130{ }^{\circ} \mathrm{C}$, bottom: Argyle 57 (ecl); $\left.T_{N} 1145^{\circ} \mathrm{C}\right)$. Types of diagrams as in Fig. 3. Dashed lines are

preferred references for regular behaviour as found in Eqs. 1, 3, 6 and 8. Red: core, blue: rim, green: intermediate. Regular diamonds generally are found to have nitrogen aggregation temperatures between ca. 1120 and $1220^{\circ} \mathrm{C}$
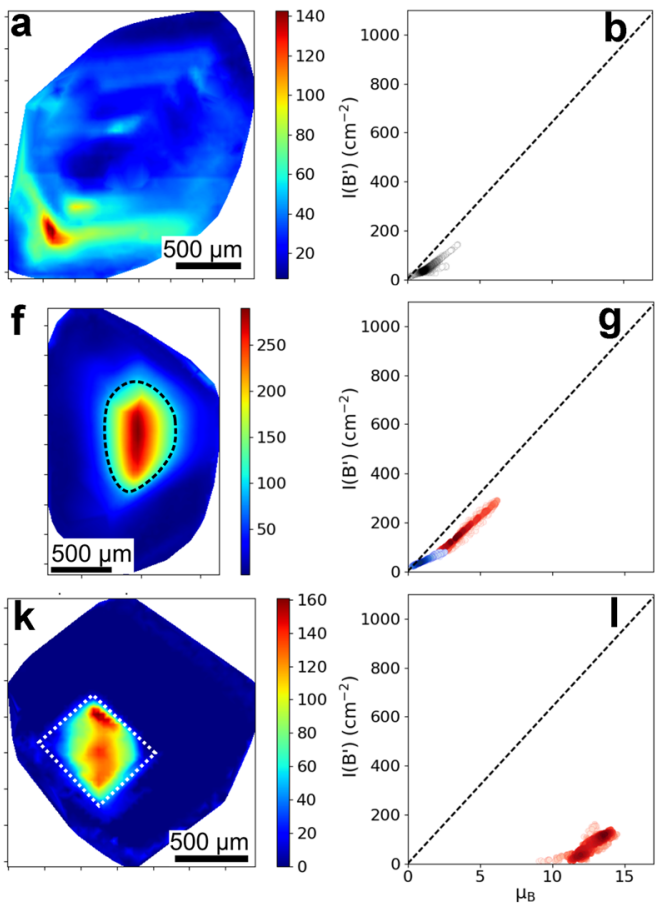
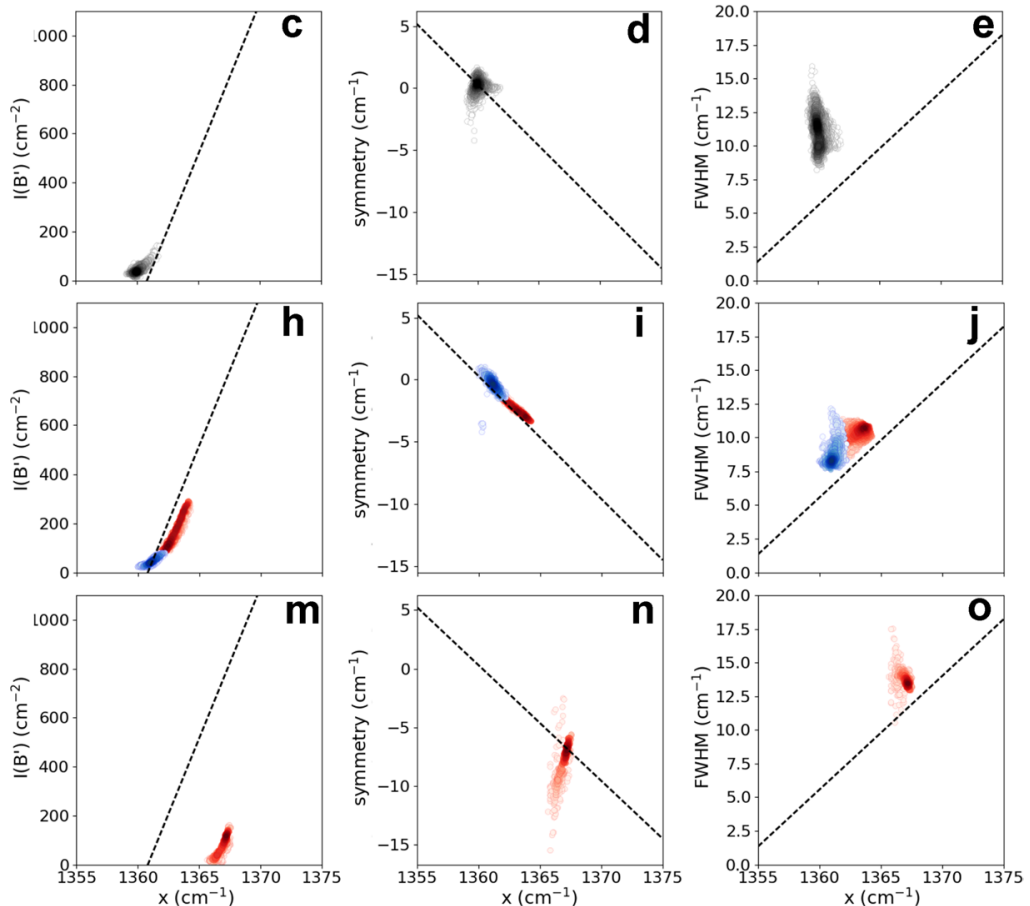

Fig. 6 Examples of irregular platelet behaviour. Types of diagrams as in Fig. 3. Dashed lines are preferred references for regular behaviour as found in Eqs. 1, 3, 6 and 8. Top: Argyle 140 (per; whole sample; this sample does not show distinct core and rim zones, $T_{N} 1225^{\circ} \mathrm{C}$ ), centre: Diavik 122 (per; $T_{N}$ core: $1260{ }^{\circ} \mathrm{C}$, rim: $1225^{\circ} \mathrm{C}$ ), bottom: Argyle 78 (core only; per; fully aggregated). Irregular diamonds generally occur at temperatures above ca. $1220^{\circ} \mathrm{C}$ 

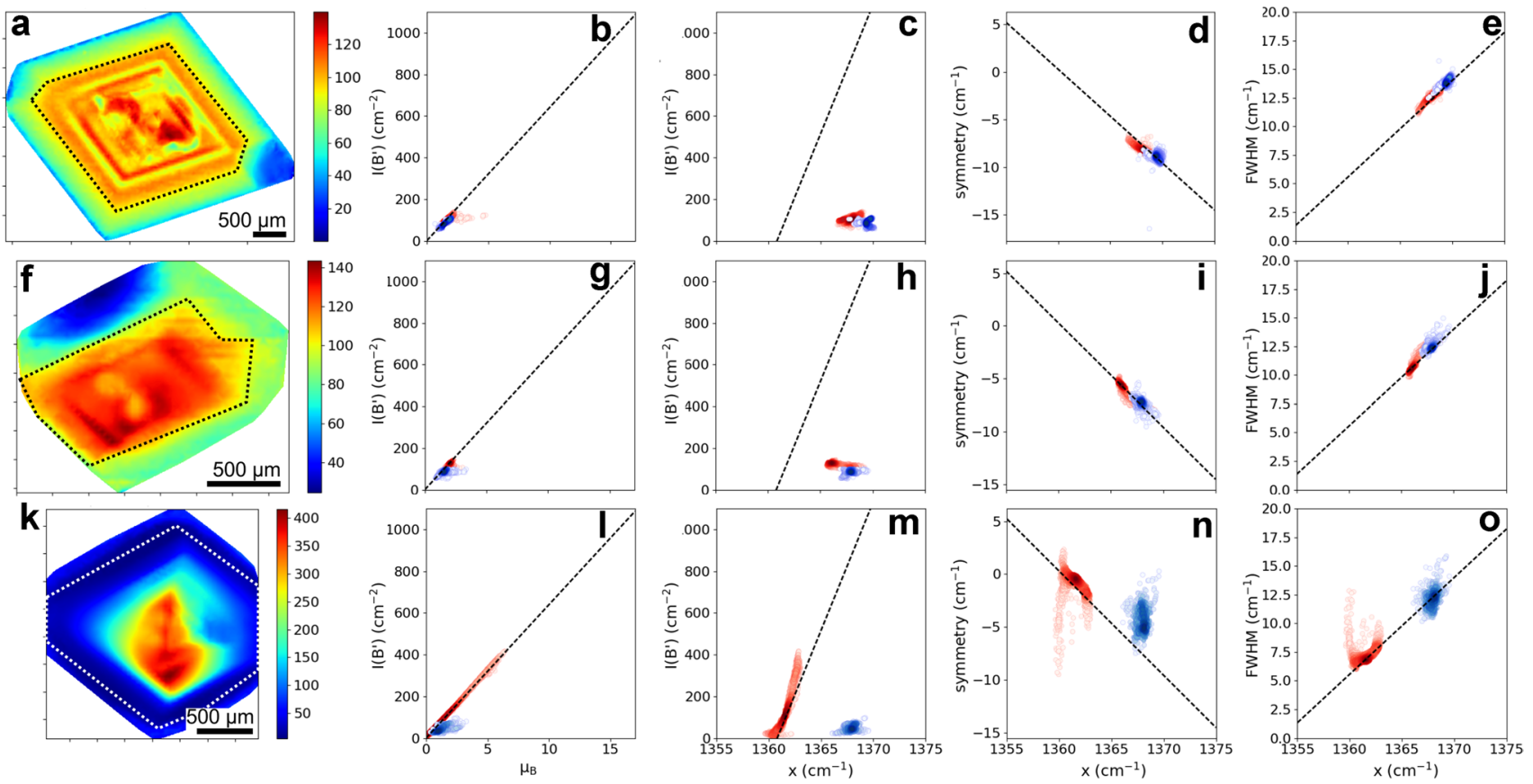

Fig. 7 Examples of subregular platelet behaviour. Types of diagrams as in Fig. 3. Dashed lines are preferred references for regular behaviour as found in Eqs. 1, 3, 6 and 8. Top: Mir 1164 (ecl, $T_{N}$ core: $1080^{\circ} \mathrm{C}$, rim: $1070{ }^{\circ} \mathrm{C}$ ), centre: Mur 248 (per; $T_{N}$ core: $1090^{\circ} \mathrm{C}$, rim:

predicted by initial platelet density in diagram two, platelet size is often nearly constant with a slight tendency for platelets to become smaller. It is easy to understand why platelets would decrease in size during degradation. However, it is unclear why they appear to have grown in some cases. It may be that a process similar to Ostwald ripening is responsible. This could result in preferential degradation of small platelets and further growth of large platelets, altering the pre-existing platelet size distribution. Lower than expected platelet peak positions in diagram two were only observed for peaks with a small integrated area, suggesting that overall platelet density is low. Thus, a process such as Ostwald ripening would require fast diffusion of interstitials or vacancies between platelets. Model temperatures above $1220^{\circ} \mathrm{C}$ were determined for diamonds in this subset.

It has been suggested that the structure of platelets grown experimentally at high temperatures and pre-existing natural platelets treated under similar conditions is subtly different to that of the defects occurring in diamonds annealed at much lower temperatures in the mantle (Kiflawi et al. 1998). These structural changes also lead to the introduction of an additional small absorption band at ca. $1488-1490 \mathrm{~cm}^{-1}$ and the disappearance of the band at $328 \mathrm{~cm}^{-1}$ that is observed in natural, platelet containing diamonds. The latter is below the wavenumber range recorded in our laboratory but IR analysis of several high temperature diamonds conducted in our lab using up to 2000 scans yields a small peak at ca.
$1080{ }^{\circ} \mathrm{C}$ ), bottom: Diavik 143 (per; $T_{N}$ core: $1160^{\circ} \mathrm{C}$, rim: $1100{ }^{\circ} \mathrm{C}$ ), note: the core of this sample is regular, whereas the rim is subregular. Subregular diamonds generally occur at temperatures below ca. $1120^{\circ} \mathrm{C}$

$1490-1493 \mathrm{~cm}^{-1}$, assumed to be the same feature. This band is often underlain by a broader absorption between ca. 1480 and $1560 \mathrm{~cm}^{-1}$ and accompanied by a narrower but weak absorption at ca. $1547 \mathrm{~cm}^{-1}$.

Subregular diamonds (see Fig. 7) are largely regular with respect to diagram one. A small number of possible exceptions can be found in our data, one of which is DVK 143, shown in Fig. 7k-o. The core of this diamond is regular but the subregular rim shows a number of points below the trend defined as regular. The main distinguishing feature, however, is the fact that platelets in subregular diamonds are smaller than in regular diamonds according to our diagram two. Their low mantle storage temperatures (below ca. $1120^{\circ} \mathrm{C}$ ) and general agreement with the trend in diagram one suggest that platelet degradation is unlikely to be the cause for this. One explanation could be that, rather than having been degraded, the platelets in these samples have not fully grown.

It has been suggested by Howell et al. (2012) that platelet growth may depend on diamond growth habit with cuboid sectors showing a significantly reduced platelet signal compared to contemporary octahedral sectors in one mixed habit diamond. Platelets in both the cuboid and octahedral growth sectors of the single diamond plate presented in Howell et al. (2012) fall below the Woods (1986) line and display very high platelet peak positions. This implies that the diamond 
studied by Howell et al. (2012), is subregular. However, the majority of our data is based on octahedrally grown diamonds. Thus, we propose that the diamond examined in Howell et al. (2012) might represent an extreme example of subregularity and that subregular behaviour might be amplified in cuboid growth. Yet, it should be noted that the origin and thus the age of this stone in Howell et al. (2012) is unknown. With the data presented by the authors and using reasonable mantle storage durations between 1 and $3 \mathrm{Ga}$, we obtain model temperatures between 1120 (average for $1 \mathrm{Ga}$ ) and $1090^{\circ} \mathrm{C}$ (average for $3 \mathrm{Ga}$ ), consistent with our range of subregular diamonds.

A crucial consequence of the above observations is that not all diamonds that fall below the trend in diagram one are irregular in the usual sense. The relationship between B-centres and platelets as described by our diagram one alone might not be sufficient to determine whether some diamonds are regular. In fact, a similar conclusion was drawn by Vasilyev et al. (2005) and Vasilev and Sofroneev (2007).

Vasilev and Sofroneev (2007) suggest that instead of being degraded, platelets did not develop fully in irregular samples. However, using their IR data on nitrogen aggregation and the same model age of $2.9 \mathrm{Ga}$ that is used in our lab for samples from Mir (see Table 1), we obtained model temperatures in the range $1060-1130{ }^{\circ} \mathrm{C}$, which is in good agreement with the range found here for subregular diamonds. This observation suggests that the conclusion of Vasilev and Sofroneev (2007) is only valid for low temperature or subregular samples.

These authors base their conclusion on very weak additional peaks in IR spectra of diamonds from the Mir mine (Siberia) at $1520-1525$ and $1545-1550 \mathrm{~cm}^{-1}$, named $\mathrm{E}$ and $\mathrm{F}$, respectively. It is unknown which defect causes these peaks but it is speculated that they could be due to defects involving smaller clusters of interstitials. These defects could act as a precursor to platelets.

Additional IR peaks at ca. 1524 and $1550 \mathrm{~cm}^{-1}$ assumed to be the same as E and F reported by Vasilev and Sofroneev (2007), can be found in all our diamonds in the subregular group and in some lower temperature regular diamonds but in none of the irregular diamonds. An example is shown in Fig. 8. The peak at ca. $1550 \mathrm{~cm}^{-1}$ is similar to a peak sometimes observed in high temperature samples but lacks the broad underlying shoulder observed in the latter. Where platelet behaviour varies within samples, such as in sample Diavik 160, only subregular zones exhibit the $\mathrm{E}$ and $\mathrm{F}$ peaks.

If the $\mathrm{E}$ and $\mathrm{F}$ absorptions described by Vasilev and Sofroneev (2007) and observed in our data are, in fact, due to a precursor defect of platelets, their intensity is expected to be proportional to the deviation from regular behaviour. To test this, the $\mathrm{E}$ and $\mathrm{F}$ peaks were fitted in a similar manner to the platelet peak but a correlation could not be established. There is, however, a positive linear correlation between the

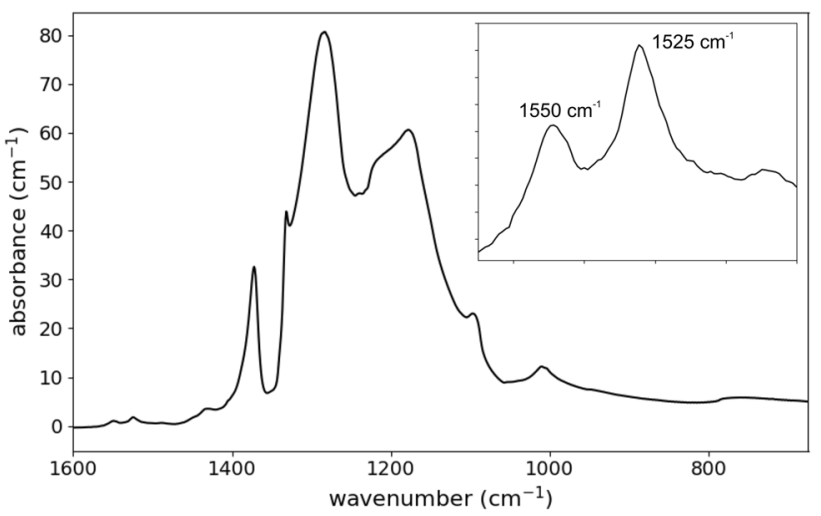

Fig. 8 Spectrum of Diavik 128. Note the additional peaks at 1550 and $1525 \mathrm{~cm}^{-1}$ in this subregular sample. It contains in excess of 2000 ppm nitrogen, $49 \%$ of which is in the form of B-centres, resulting in a model temperature of $1090{ }^{\circ} \mathrm{C}$. Spectrum obtained at $2 \mathrm{~cm}^{-1}$ resolution, using a $60 \mu \mathrm{m}$ wide aperture and 2000 scans

combined peak area of $\mathrm{E}$ and $\mathrm{F}$ and the platelet peak area. It follows that the $\mathrm{E}$ and $\mathrm{F}$ peaks are likely related to platelets but their role as a precursor to platelets could not be verified even though they appear to anneal out at temperatures that coincide roughly with the transition from subregular to regular. It should be noted that $\mathrm{E}$ and $\mathrm{F}$ are very small and quantification is not straightforward.

The existence of subregular diamonds with a lower than expected platelet density implies that in some rare cases, platelet formation is slower than the formation of B-centres. This does not agree with the conclusion drawn by Goss et al. (2003) that nitrogen aggregation is driven by the growth of platelets. The authors suggest that platelets can be viewed as partial dislocations the climb of which releases vacancies and leads to platelet growth. These vacancies are trapped by A-centres to form B-centres. If this is the case, it seems impossible that the amount of platelets is lower than expected for a given amount of B-centres in a non platelet degraded sample. Alternatively, a process other than platelet growth would be required to generate additional vacancies needed to drive nitrogen aggregation through the Goss et al. (2003) model. This inconsistency requires further study.

Quantifying deviation from regular In addition to the qualitative observations made above, deviation from regular can be quantified. Diamond Mur 235 is used as a reference for regular platelet behaviour in terms of the relation between peak position and area (diagram two). The expected peak position can be determined using the expected platelet peak area, derived from $\mu_{B}$ (Eqs. 1 and $3)$. The horizontal deviation from this reference can be shown to be small $\left(0 \pm 2 \mathrm{~cm}^{-1}\right)$ for regular diamonds and increases both towards very low and very high model temperatures (see Fig. 9). Values up to 8 and ca. $2.5 \mathrm{~cm}^{-1}$ for subregular and irregular samples, respectively were 


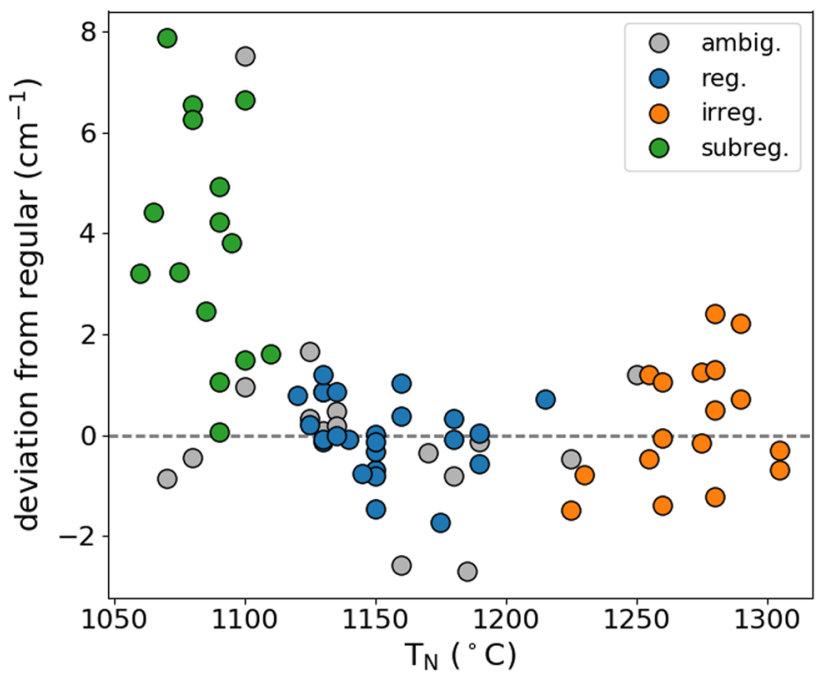

Fig. 9 Deviation from regular platelet behaviour in diagram two with model temperature derived from nitrogen aggregation. Deviation calculated as distance to line defined by Eq. 3. Regular samples (blue) show very little deviation $\left(0 \pm 2 \mathrm{~cm}^{-1}\right)$, whereas in both irregular (orange) and subregular (green) samples, the platelet peak can be shifted towards higher wavenumbers

observed in our dataset. This equates to mean platelet diameters being smaller than expected in some of the subregular samples by almost $150 \mathrm{~nm}$. However, these values do not represent the full range of deviation from regular but are based on kernel density estimation. Individual spectra can deviate more strongly from the reference (for example, see Fig. 7b, f). The size of platelets in irregular samples is generally unchanged or decreased slightly.

Out of the 40 diamonds studied, five were found to be unambiguously subregular. A further four samples appear to have some but not all characteristics of subregular diamonds. These have model temperatures close to $1120^{\circ} \mathrm{C}$, the estimated transition between subregular and regular platelet behaviour. A total of nine samples was found to be regular and another nine samples can be described as irregular. The latter includes most but not all samples from Argyle studied here and only a few diamonds from other localities. The remaining samples show mixed behaviour with regular core and subregular rim zones or irregular core and regular rim zones. Model temperatures vary considerably within these diamonds, as well. One example of such diamonds is shown in Fig. 10e-h. In this case, the core appears to be regular, whereas the rim is subregular.

One diamond (Mir 1525) exhibits a fully platelet degraded core, an intermediate zone with low nitrogen concentration that is likely regular and a subregular rim. The model temperature obtained for the core of ca. $1190^{\circ} \mathrm{C}$ is comparatively low for an irregular diamond. Both total nitrogen concentration and aggregation state (exceeding 1000 ppm, ca. $90 \%$ B) should allow for a good estimate of 

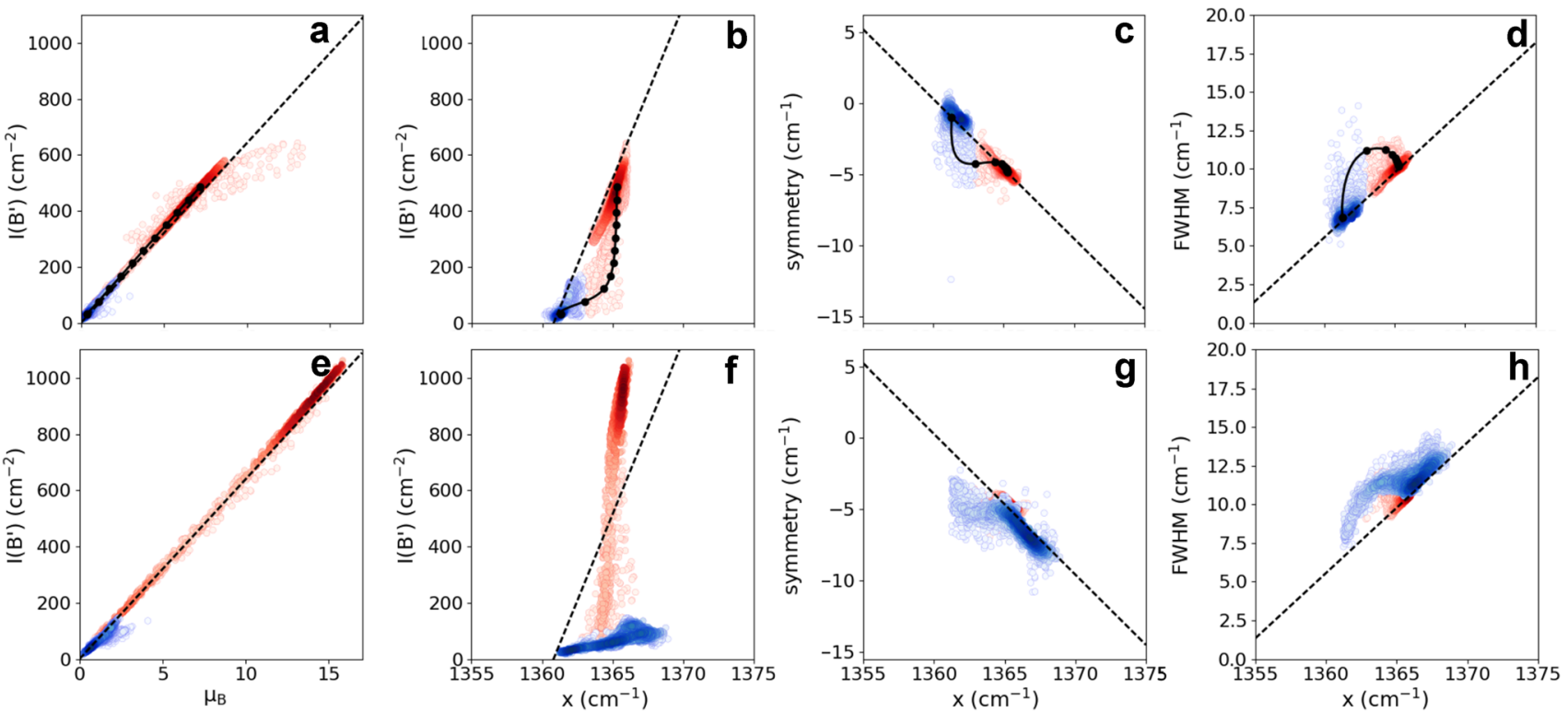

Fig. 10 Example of 'mixing zones' problem and preservation of different types of platelet behaviour within a single sample. Top a-d example of 'mixing zones' problem (sample Mur 33; $T_{N} 1135{ }^{\circ} \mathrm{C}$ ). Mixing lines (solid) modelled by adding representative platelet peaks from the core and rim, represented by the centre of the red and blue

model temperature. In this case, plastic deformation could play a role in platelet degradation. These examples illustrate that the growth history of natural diamonds can be very complex, preserving various stages of annealing.

In some diamonds, the problem of "mixing zones" (Kohn et al. 2016) is evident. It arises from analysing a mixture of neighbouring growth zones in FTIR if plates are thick and not purely central. The measured spectra exhibit nitrogen concentrations and aggregation states intermediate between the two (or more) zones analysed, resulting in artefacts in model temperature. A similar situation applies to platelet characteristics. It can be shown that mixing between two neighbouring zones is linear in diagram one (see Fig. 10a) but more complex in the remaining three diagrams (Fig. 10b-d). The example shown here is sample Mur 33 that has markedly different core and rim zones. These were used to model the result of "mixing" two different platelet peaks, one equivalent to the peak found in the core, the other using characteristics from the rim. Combining these end-members in different proportions leads to the "mixing" lines shown in Fig. 10b-d, illustrating that "mixing" has to be taken into account when interpreting diagrams one to four and how to recognise it.

distributions of data points. Bottom e-h Sample DVK 160 (per; $T_{N}$ core: $1160{ }^{\circ} \mathrm{C}$, rim: $1090{ }^{\circ} \mathrm{C}$, see also Fig. 1). The core is regular, the rim appears to be subregular. Types of diagrams as in Fig. 3. Dashed lines are preferred references for regular behaviour as found in Eqs. 1, 3,6 and 8

\section{Platelet thermochronometry}

In addition to the qualitative observations made in section , we can calibrate the rate of platelet degradation as a thermochronometer. Our approach is similar to that of Taylor et al. (1990), who calibrated the rate of nitrogen aggregation for thermochronometry by combining data from natural diamonds annealed at mantle conditions over several hundred million years and diamonds annealed experimentally at much higher temperatures by Clark and Davey (1984).

In contrast to the aggregation of A-centres to B-centres which is a second-order reaction (Taylor et al. 1990), the order of the platelet degradation reaction is unknown. However, the reaction rate appears to depend on initial platelet concentration. In diagram one, platelet degraded diamonds with varying nitrogen concentrations frequently form a linear trend that is "rotated" around the origin by some angle relative to the regular trend (for examples, see Fig. 11a, b). It is assumed that diamond growth occurs rapidly enough so that the duration and temperature of annealing do not vary considerably within a given growth zone (Kohn et al. 2016). Total nitrogen concentration and aggregation state and hence the amount of platelets available for degradation, on the other hand, may vary even within a single growth zone. In other words, the amount of degradation that has taken place in a given growth zone varies with the amount of platelets present initially which is a characteristic of reactions of order higher than 0 . 


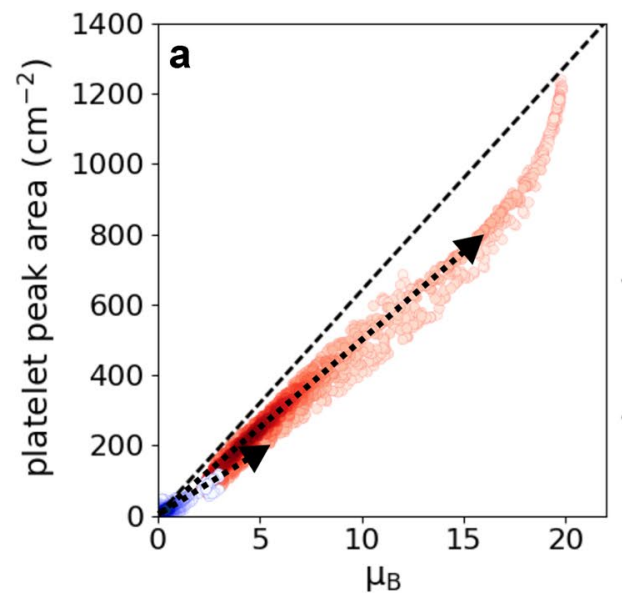

Fig. 11 Diagram one for selected samples. Dashed lines is the preferred reference for regular behaviour as found in Eq. 1. a Arg 10 (ecl; $T_{N}$ core: $1280{ }^{\circ} \mathrm{C}$, rim: $\left.1255^{\circ} \mathrm{C}\right)$, b Arg $46\left(\mathrm{ecl} ; T_{N}\right.$ intermediate: $1290{ }^{\circ} \mathrm{C}$, rim: $1280{ }^{\circ} \mathrm{C}$ ), core: DVK 122 (per; $T_{N}$ core: $1260^{\circ} \mathrm{C}$, rim:

If platelet degradation was a zeroth-order reaction so that the reaction rate is independent of initial concentration, a trend parallel to the line defined by Woods (or Eq. 1) but offset to lower $I\left(B^{\prime}\right)$ would be expected. In other words, the absolute amount of platelet degradation is the same regardless of initial concentration. In fact, this behaviour can be observed in some of our samples as well but is less common (for example, in Arg 78 and DVK 122, see Figs. 6g, 1 and 11c). Thus, we argue that platelet degradation can best be approximated as a first order reaction.

Strictly speaking, two separate rate components have to be taken into consideration to determine the amount of platelets present at any given time: (1) the positive change in platelet concentration due to nucleation and growth of new platelets, proportional to nitrogen aggregation and thus proportional to $\left[N_{A}\right]^{2}$ (with the concentration of nitrogen in A-centres $\left[N_{A}\right]$ ) and (2) the negative rate of change due to destruction of existing platelets that is proportional to the current amount of platelets, $P_{0}$.

To assess the effect of concurrent formation and destruction of platelets over time, a simple forward model was devised and tested on 28 of our samples. Using the known rate of nitrogen aggregation (Taylor et al. 1990, 1996) and Eq. 1, the overall amount of platelet produced in each time step can be estimated. The sum of these newly formed platelets and platelets present from previous time steps is then degraded. Using the known mantle storage duration and temperature of each sample, our model can be used to replicate the trend observed in diagram one by systematically varying $k_{p}$, the rate constant of platelet degradation (for example, see Fig. 12a).

Figure $12 \mathrm{~b}-\mathrm{d}$ illustrate the principles of the forward modelling in more detail for a hypothetical sample annealed at

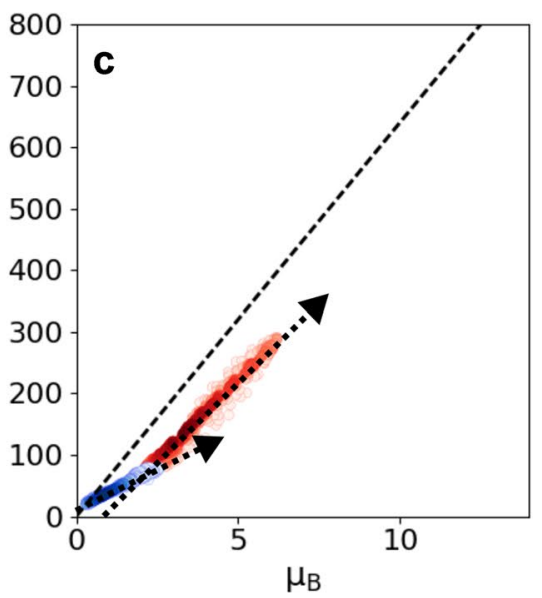

$1225^{\circ} \mathrm{C}$ ). red: core, blue: rim. Data in $\mathbf{a}$ and $\mathbf{b}$ shows a slope consistent with first order reaction kinetics, whereas in $\mathbf{c}$, the core is consistent with a zeroth order reaction (as emphasised by dashed arrows)

$1280{ }^{\circ} \mathrm{C}$ with total nitrogen concentrations up to $1800 \mathrm{ppm}$. For clarity, a slightly higher rate constant for platelet degradation than the best fit determined for Arg 10 as per Fig. 12a was used here. The grey lines in panel $b$ are isochrons that represent the state of platelet degradation after time intervals between 100 and $400 \mathrm{Ma}$. The trend observed for our natural samples in diagram one and panel a represents the final 'isochron'.

Since the rate of nitrogen aggregation increases with $\left[N_{A}\right]^{2}$ (Taylor et al. 1990), aggregation progresses very quickly initially and slows down as the concentration of A-centres decreases (see Fig. 12c). Thus, the bulk of the B-centres are formed within the first ca. $100 \mathrm{Ma}$. The rate of platelet formation in response to nitrogen aggregation is unknown and the existence of subregular diamonds demonstrates that it is not instantaneous at low temperatures. However, at temperatures compatible with platelet degradation, it is probably very high and can be ignored safely. If this is the case, a large majority of platelets are formed very quickly in the early stages of nitrogen aggregation.

Figure $12 \mathrm{~d}$ shows the evolution of platelet peak area over time under the same conditions, accounting for continued nitrogen aggregation (dashed lines) and assuming instantaneous aggregation (solid lines). As can be seen, the two models differ significantly for an initial period of ca. $100 \mathrm{Ma}$ but predict very similar platelet peak areas thereafter. The same conclusion can be drawn when examining platelet evolution in terms of diagram one (Fig. 12b). Since this diagram shows the relationship between B-centres and platelets, the evolution of a diamond with a given total nitrogen concentration starts in the bottom left corner, then moves along the regularity line until the rate of nitrogen aggregation and hence platelet formation decrease enough for degradation to 

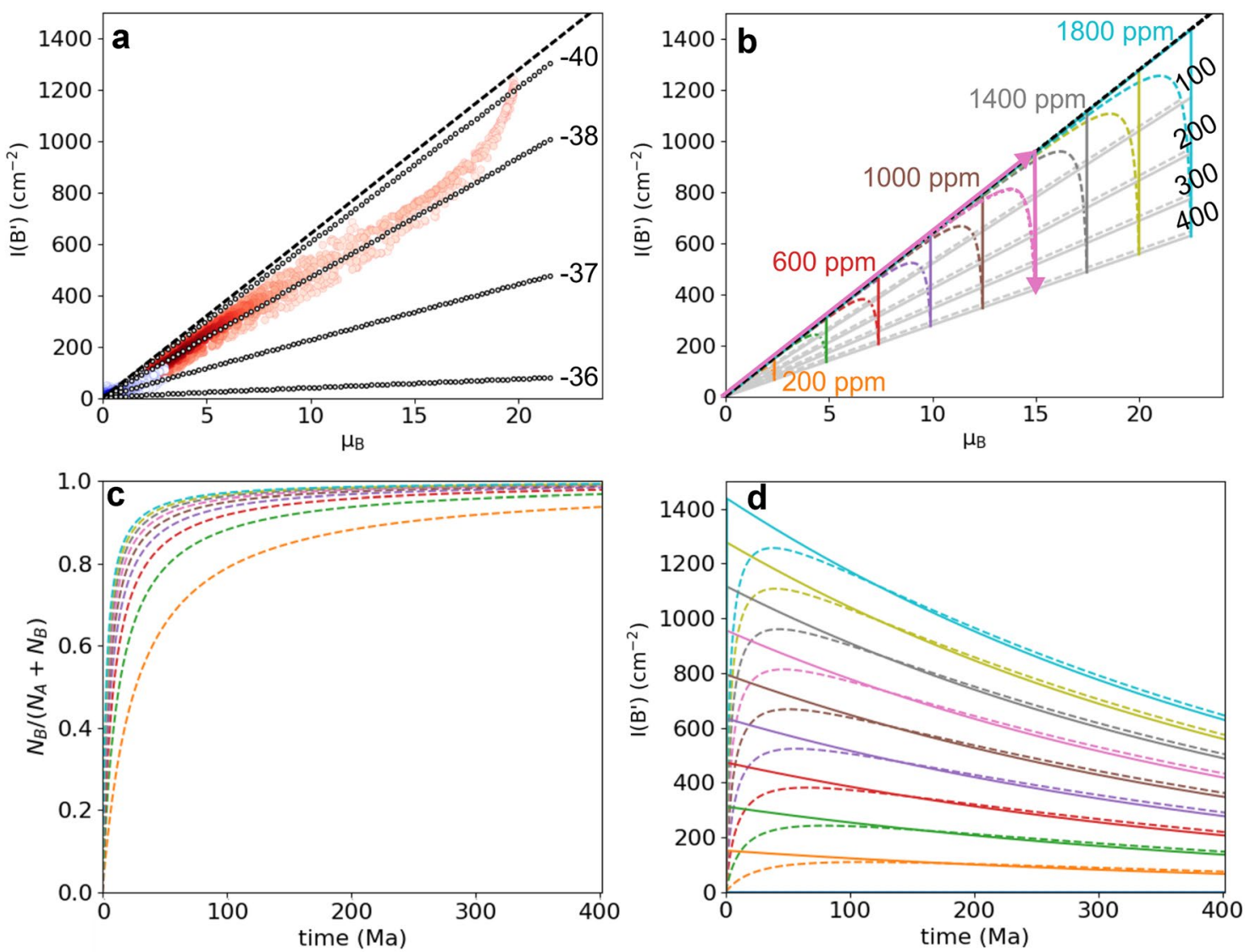

Fig. 12 Forward model of platelet degradation in sample Arg 10 at $1280^{\circ} \mathrm{C}$. a platelet degradation predicted by forward modelling using different exemplary values for $\ln \left(k_{P}\right)$ (see labels) and comparison to observed data (red: core, blue: rim) to illustrate the fitting process, $\mathbf{b}$ development of B-centres $\left(\mu_{B}\right)$ and platelet peak area over time using instantaneous (solid) and continuous (dashed) nitrogen aggregation for nitrogen concentrations ranging from 200 (orange) to $1800 \mathrm{ppm}$

(light blue). To highlight one example, pink arrows mark platelet development for $1200 \mathrm{ppm}$ total nitrogen. Grey lines are isochrons for 100-400 Ma for instantaneous (solid) and continuous (dashed) nitrogen aggregation. $\mathbf{c}$ continuous nitrogen aggregation over time for the same nitrogen concentrations as in $\mathbf{b}, \mathbf{d}$ development of platelet peak area over time for the same nitrogen concentrations assuming instantaneous (solid) and continuous (dashed) nitrogen aggregation

dominate the overall rate of platelet change. Despite the path differences between the two models, corresponding isochrons (grey) in Fig. 12b are almost indistinguishable.

Another interesting observation is that, due to the interplay between the changing rates of platelet formation and destruction, forward modelling predicts slightly concave down isochrons when, in fact our data, if curved, is always concave up (compare Fig. 11).

Thus, there is no advantage in using a more complicated model including continuous nitrogen aggregation since the simpler model leads to results indistinguishable within the uncertainties involved in platelet measurement. In addition, replicating the observed data by manual forward modelling is subjective and difficult in samples with very subtle degrees of platelet degradation and the simple model is much more straightforward to use as a thermochronometer.

Hence, we use a simple first-order rate equation of the following form to describe platelet degradation:

$P_{t}=P_{0} \times \mathrm{e}^{-k_{P} t}$

with the initial amount of platelets $P_{0}$ (in terms of platelet peak area in $\mathrm{cm}^{-2}$, determined from the absorption due to B-centres using Eq. 1), the present amount of platelets $P_{t}$ (in $\mathrm{cm}^{-2}$ ), the rate constant of platelet degradation $\left(k_{P}\right)$ and duration $\mathrm{t}$ (in seconds). We define the rate constant as

$k_{P}=\frac{\ln \left(\frac{P_{0}}{P_{t}}\right)}{t}$

This rate constant and the temperature derived from nitrogen aggregation $\left(T_{N}\right)$ can then be used to construct an Arrhenius diagram (see Fig. 13). One important limitation of this approach is the uncertainty in mantle storage duration. Especially the age (and hence storage duration) of rim zones that show markedly different model temperatures to their core is likely to be an overestimate as is discussed in Kohn et al. 


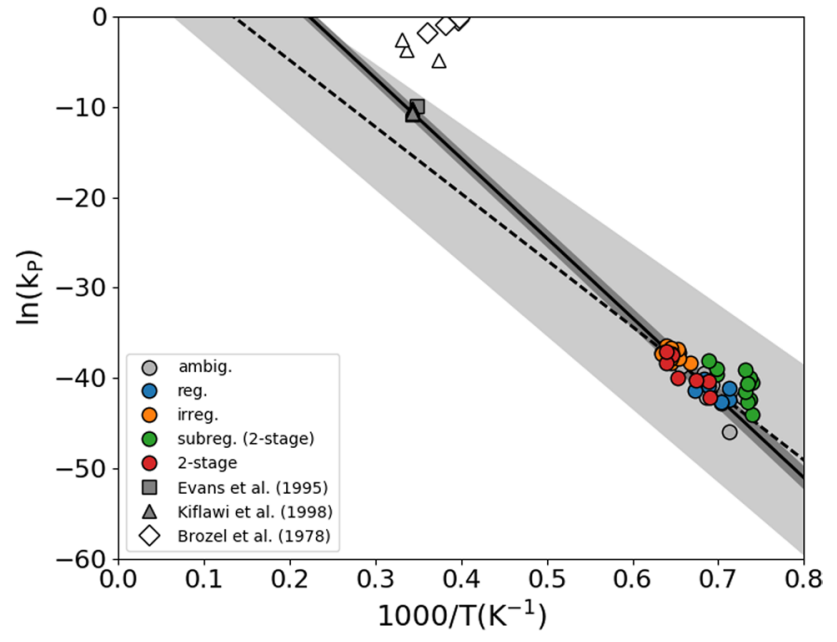

Fig. 13 Arrhenius plot for the platelet degradation reaction, combining data from natural diamonds (circles) and experimental data by Evans et al. (1995) (squares), Kiflawi et al. (1998) (triangles) and Brozel et al. (1978) (diamond symbols). Grey symbols indicate experiments conducted under diamond-stable conditions, open symbols indicate experiments conducted under graphite-stable conditions. The kinetic rate constant, $k_{P}$, was calculated according to Eq. 11. Solid line: best fit to the experimental data and our data of irregular and regular diamonds, yielding $E_{\mathrm{a}} / R=88.4 \pm 0.9 \times 10^{3} \mathrm{~K}$ and $\ln \left(A_{P}\right)=19.7 \pm 0.5 \quad\left(R^{2}=0.996\right)$. Dashed line: best fit to our data of irregular and regular diamonds only, yielding $E_{\mathrm{a}} / R=73.8 \pm 7.2 \times 10^{3} \mathrm{~K}$ and $\ln \left(A_{P}\right)=9.9 \pm 4.8\left(R^{2}=0.820\right)$. Shaded areas applying $1 \sigma$ errors to values of $E_{\mathrm{a}} / R$ and $\ln \left(A_{P}\right)$

(2016). In an attempt to correct for this uncertainty, a model of diamond growth and annealing in two stages was applied (Kohn et al. 2016). This model uses the total nitrogen concentration and aggregation state of both the core and rim to estimate the age of the rim, assuming a constant temperature over the whole annealing duration. Even though the growth history of the diamond may be more complex than this simple two-stage model, it is without doubt a better approximation than assuming the same duration of mantle storage for core and rim. The slope and intercept of the Arrhenius diagram thus constructed using our data only yield an activation energy $E_{\mathrm{a}} / R$ of $73.8 \times 10^{3} \mathrm{~K}^{-1}$ and a pre-exponential factor $\ln \left(A_{P}\right)$ of 9.9 , respectively $\left(R^{2}=0.820\right.$, see dashed line in Fig. 13).

Several experimental studies were performed on natural diamonds to investigate platelet formation and degradation. Some of these were likely performed under graphite-stable conditions (Brozel et al. 1978). It has been proposed that outside the stability field of diamond, the rate of platelet degradation is increased, potentially by several orders of magnitude (Evans et al. 1995). This agrees with Fig. 13 which shows that the rate constant is much higher in experiments performed under graphite-stable conditions (white symbols) than the other experimental (grey symbols) data despite similar temperatures. As a consequence, some of the experimental data may be unreliable and were not used in our calibration (notably that of Brozel et al. 1978 and most of the data in Kiflawi et al. 1998). Thus, we rely on experimental data by Evans et al. (1995) and Kiflawi et al. (1998), including only the experimental runs conducted at diamond stable conditions from the latter.

Furthermore, platelet peak height rather than area was reported for most samples. This poses a problem because the platelet peak is highly variable in width and shape. Hence, peak area would be a better descriptor than peak height. However, peak height was used where necessary for lack of more dependable data. Thus, $E_{\mathrm{a}} / R$ and $\ln \left(A_{P}\right)$ were also obtained for our new data and the experimental data, yielding $88.4 K^{-1}$ and $19.7\left(R^{2}=0.996\right.$, see solid line in Fig. 13) and are in general agreement with the values obtained from the natural samples only.

Subregular samples generally lie above the trend line, as is to be expected. They can show a lower than expected platelet peak area despite not being degraded. Hence, they were not used in the calibration and are shown in Fig. 13 for comparison only.

Thus, using Eq. 11 and the Arrhenius relationship

$k_{P}=A_{P} \times \mathrm{e}^{\frac{-E_{\mathrm{a}}}{\mathrm{RT}}}$

we can now obtain platelet degradation temperatures using the following equation

$T_{P}=\frac{E \mathrm{a} / R}{\ln \left(A_{P}\right)-\ln \left(\frac{\ln \left(P_{0} / P_{t}\right)}{t}\right)}$

Apart from the subregular samples, all annealing temperatures as determined from nitrogen aggregation can be reproduced within $\pm 50^{\circ} \mathrm{C}$ (see Fig. 14) using Eq. 13 and values for $E_{\mathrm{a}} / R$ and $\ln \left(A_{P}\right)$ as stated above. Most temperatures lie within a smaller range of $\pm 30^{\circ} \mathrm{C}$. For subregular diamonds, temperature will be overestimated using platelet degradation. This is expected since even though no degradation has taken place, they sometimes show slightly smaller platelet peak areas than would be the case for a regular diamond.

Compared to the study by Taylor et al. (1990) on nitrogen aggregation, our Arrhenius diagram displays a larger amount of scatter. It is possible that other factors contributing to platelet degradation, such as plastic deformation, are responsible. These were not taken into account here but are likely to have an impact on the accuracy of a platelet degradation thermochronometer. An assessment of the role of plastic deformation in platelet degradation is currently under way.

Another source of uncertainty stems from the mantle storage durations used to obtain model temperatures for core zones and also to estimate the age of the corresponding rim. The amount of data on both inclusion and eruption ages is generally limited. Nevertheless, the resulting mantle storage 


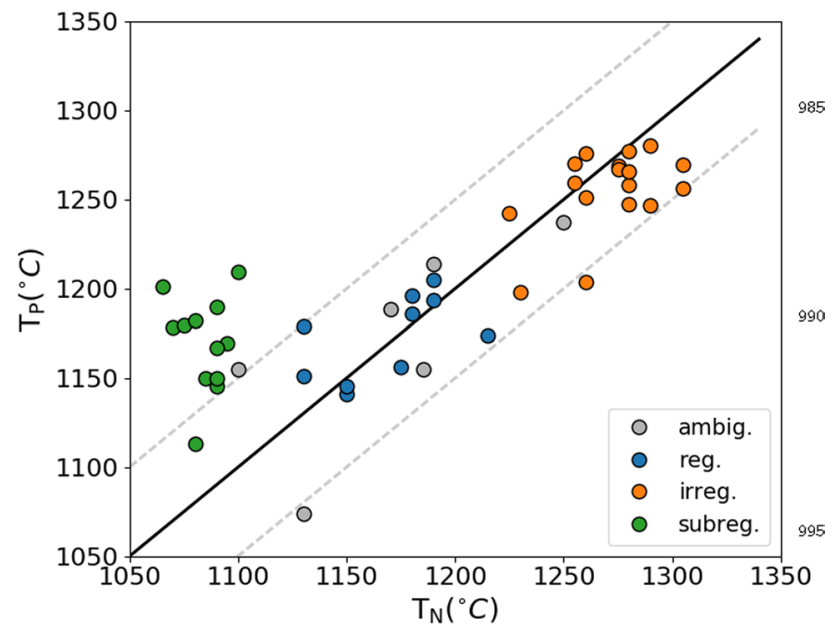

Fig. 14 Comparing temperature from platelet degradation $\left(T_{P}\right.$, calculated using Eq. 13 and $E_{\mathrm{a}} / R$ and $\ln (A)$ derived from the solid line in Fig. 13) and temperature from nitrogen aggregation $\left(T_{N}\right.$, calculated according to Taylor et al. (1990)). Dashed lines indicate $\pm 50^{\circ} \mathrm{C}$

duration is applied to a whole suite of diamonds that are assumed to have grown simultaneously. The presence of late stage overgrowth in many diamonds (such as in DVK 160, see Figs. 1 and 10e-h) demonstrates that, even within a single suite of diamonds, there is evidence for multiple growth stages that may have occurred at significantly different times. This is unlikely to have a noticeable effect on diamonds with long mantle storage durations (above ca. $1 \mathrm{Ga}$ ) but could be relevant for the Argyle samples since their mantle storage duration is believed to be very short (compare Table 1).

Furthermore, the mechanism of platelet degradation could vary with nitrogen concentration or temperature. In fact, there is evidence that the kinetics of the reaction might not be as straightforward as proposed here. As explained earlier and shown in Fig. 11, the amount of degradation is dependent on the initial platelet concentration in most but not all cases, indicated by a trend in diagram one that is oblique to the regularity line. Some samples, however, show a shift from oblique to parallel to the regularity line with increasing $\mu_{B}$ (e.g. Fig. 11c), suggesting a potential change in mechanism, for example with platelet size.

So far, platelet degradation has only been employed as a thermometer, i.e. temperatures of mantle storage were obtained using a mantle storage duration determined independently. The reverse calculation is more challenging but can be applied to the data reported in Navon et al. (2017). The authors report current platelet peak areas $\left(P_{t}\right)$ of ca. $1 \mathrm{~cm}^{-1}$ and initial peak areas $\left(P_{0}\right)$ of ca. $500 \mathrm{~cm}^{-1}$ based on the amount of B-centres present. Combining this data with their temperature estimate of $1640{ }^{\circ} \mathrm{C}$ yields a mantle storage duration of ca. $64 \mathrm{ka}$ which is in reasonable agreement

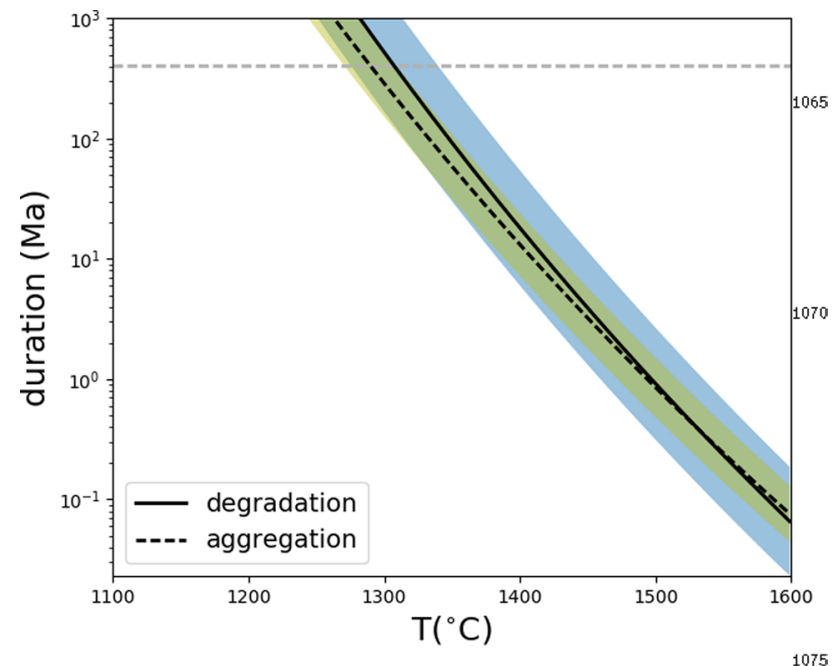

Fig. 15 Comparing the kinetics of platelet degradation and nitrogen aggregation for sample $\operatorname{Arg} 46\left(\mathrm{ecl},\left[N_{T}\right]=200 \mathrm{ppm},\left[N_{A}\right]=10 \mathrm{ppm}, P_{0}\right.$ $=153 \mathrm{~cm}^{-2}, P_{t}=17 \mathrm{~cm}^{-2}$ ) using values for $E_{\mathrm{a}} / R$ and $\ln (A)$ from this study and Taylor et al. (1996). Shaded areas represent errors (green: nitrogen aggregation, blue: platelet degradation).Taylor et al. (1996) does not state errors, estimates used here are based on the errors given in Taylor et al. (1990). Grey dashed line represents $402 \mathrm{Ma}$, the mantle storage duration assumed for eclogitic Argyle samples

with their estimate of the duration of voidite growth of ca. 0.2-10 ka depending on the size of the voidite.

In principle, it should be possible to combine the rates of nitrogen aggregation and platelet degradation into a single thermochronometer. Both rates depend on duration and temperature and the activation energies were determined for both processes. If we assume that they occur simultaneously, i.e. over the same time scale and at the same conditions, we should be able to solve for both unknowns. However, the activation energies of the two processes are remarkably similar.

Figure 15 shows the relationship between duration and temperature for both platelet degradation and nitrogen aggregation using sample Arg 46 as an example. This diamond yields similar temperatures using nitrogen aggregation and platelet degradation $\left(T_{N}=1290{ }^{\circ} \mathrm{C}, T_{P}=1307^{\circ} \mathrm{C}\right)$. The two lines represent combinations of duration and temperature that would all lead to the extent of nitrogen aggregation and platelet degradation found in this diamond. In theory, the cross-over between them should yield the duration and temperature at which both are satisfied. However, it occurs at an unrealistically high temperature and short duration of well over $1500{ }^{\circ} \mathrm{C}$ and under $1 \mathrm{Ma}$. As can be seen, the slope and intercept of the two lines, determined by $E_{\mathrm{a}} / R$ and $\ln (A)$ of the two processes are very similar. As a result, even a small error causes the cross-over to occur at vastly different conditions. The shaded areas represent $1 \sigma$ errors for both processes. The fact that the activation energies of platelet 
degradation and nitrogen aggregation are so similar could suggest that both reactions operate by the same rate-limiting mechanism.

Despite these limitations, it is possible to use platelet degradation to estimate mantle storage temperatures. This is particularly beneficial if nitrogen is fully aggregated, so that nitrogen aggregation can not be used to accurately determine the diamond's mantle storage temperature. An example where this is the case is diamond Argyle 78 (see Fig. 6). The core of this sample is highly platelet degraded and Eq. 13 implies a temperature of ca. $1285^{\circ} \mathrm{C}$. This temperature is within error of the minimum temperature from nitrogen aggregation of $1305^{\circ} \mathrm{C}$ given by Bulanova et al. (2018) for the same sample. The minimum temperature is based on the detection limit of A-centres, i.e. the maximum permissible concentration of nitrogen in A-centres and is only an estimate.

Additionally, nitrogen thermochronometry is less reliable in very highly aggregated diamonds, where the signal from A-centres is low, hampering accurate determination of concentrations. Under these circumstances, our newly developed platelet degradation thermochronometer is likely to provide more reliable results.

\section{Conclusions}

Because of a notable improvement in data processing, namely a more thorough and automated examination of the platelet peak in IR spectra, we are now able to better understand the systematics of platelet peak variation. Speich et al. (2017) provides a comprehensive analysis of the relationship between platelet peak area, position, width and symmetry in IR and the actual size and size distribution of platelets, enabling much better interpretation of our data.

The most important qualitative conclusion that can be drawn is that the behaviour of platelets in diamond depends on mantle storage temperature and duration. Three different types of behaviour were found to occur within certain temperature regimes determined by nitrogen aggregation thermometry. Our diagrams one to three (see Fig. 3) can be used to identify the type of behaviour present and can thus be an indication of temperature regime.

Regular diamonds occur over a wide temperature range between ca. 1120 and $1220^{\circ} \mathrm{C}$. In addition to following the trend defined by Woods (1986) that is widely used to assess regularity, they show a correlation of platelet density with platelet size. Subregular diamonds are described here for the first time. They occur at low mantle residence temperatures and share some of the characteristics of regular diamonds. However, their platelet size is smaller than expected and they can show lower than expected platelet peak areas, indicating that there is a potential for further platelet growth.
At high temperature, with the onset of platelet degradation, platelet density can decrease dramatically, producing Irregular diamonds. There is a small tendency for platelet size to be decreased in these diamonds as well. Additionally, the platelet peak is markedly broader in irregular diamonds as was also observed in heat-treated natural diamonds (Fisher 2009). Hence, both platelet growth and degradation can involve changes in platelet size.

This suggests that platelets can be used to reveal and constrain the complex growth history of natural diamonds. In some of the samples studied here, significantly different platelet and nitrogen aggregation properties are preserved in different zones of a single diamond. With nitrogen aggregation thermometry alone, it is impossible to distinguish whether in these cases the rim is significantly younger than the core or whether the temperature changed, illustrating the need for further constraint on their thermal history.

We were able to calibrate a platelet degradation thermometer (see Fig. 13 and Eq. 13) that can now be used to acquire temperatures for diamonds that have experienced at least some degree of platelet degradation. Temperatures thus calculated are in good agreement with temperatures derived from the rate of nitrogen aggregation in natural diamonds. Further careful study is needed to explain the apparent change in reaction mechanism with the concentration of B-centres that could be a response to changes in platelet size. Our data does not allow for such analysis but the current simple thermometer is particularly useful, where nitrogen is highly or fully aggregated. In such cases, the concentration of A-centres, if present, can not be determined accurately and no meaningful model temperatures can be obtained from the A to B conversion. Theoretically, platelet degradation could be used as a thermochronometer, constraining the duration of mantle processes, but the uncertainties involved in its calibration make it more efficient as a mantle thermometer.

Several additional weak IR peaks that were previously described were found to be indicative of certain temperature regimes of mantle storage and can thus aid in assigning diamonds. Absorptions found at ca. 1526 and $1548 \mathrm{~cm}^{-1}$ were identified in low temperature diamonds, whereas a single weak peak at ca. $1490 \mathrm{~cm}^{-1}$, sometimes underlain by a broader absorption occurs only in high temperature samples.

Acknowledgements The authors thank Rio Tinto and the Diamond and Precious Metal Institute (Yakutsk) for the provision of the samples presented in this paper. Furthermore, we are grateful to H.J. Milledge for her comprehensive early work on characterising our Yakutian samples which helped in sample selection. We thank Charlotte Whittenbury for obtaining high quality IR maps of two diamonds from Sese and Nuzhat Tabassum for providing the spectrum shown in Fig. 8. We are also grateful to Jon Blundy who inspired us to approach platelet degradation using a forward model and Jon Goss for much appreciated input on an earlier version of this manuscript. Additionally, we thank Oded Navon and Katie Smart for valuable comments and suggestions 
that helped to improve this paper. LS thanks NERC and De Beers UK Limited for financial support.

Open Access This article is distributed under the terms of the Creative Commons Attribution 4.0 International License (http://creativeco mmons.org/licenses/by/4.0/), which permits unrestricted use, distribution, and reproduction in any medium, provided you give appropriate credit to the original author(s) and the source, provide a link to the Creative Commons license, and indicate if changes were made.

\section{References}

Allen BP, Evans T (1981) Aggregation of nitrogen in diamond, including platelet formation. Proc R Soc Lond A 375:93-104

Aulbach S, Stachel T, Creaser RA, Heaman LM, Shirey SB, Muehlenbachs K, Eichenberg D, Harris JW (2009) Sulphide survival and diamond genesis during formation and evolution of Archaean subcontinental lithosphere: a comparison between the Slave and Kaapvaal cratons. Lithos 112:747-757. https://doi.org/10.1016/j. lithos.2009.03.048

Barry JC, Bursill LA, Hutchison JL, Lang AR, Rackham GM, Sumida N (1987) On voidites-a high-resolution transmission electronmicroscopic study of faceted void-like defects in natural diamonds. Philos Trans R Soc A 321(1560):361-401. https://doi. org/10.1098/rsta.1987.0018

Berger SD, Pennycook SJ (1982) Detection of nitrogen at $\{100\}$ platelets in diamond. Nature 298(5875):635-637. https://doi. org $/ 10.1038 / 298635 \mathrm{a} 0$

Boyd SR, Kiflawi I, Woods GS (1994) The relationship between infrared-absorption and the A defect concentration in diamond. Philos Mag B 69(6):1149-1153. https://doi.org/10.1080/01418 639408240185

Boyd SR, Kiflawi I, Woods GS (1995) Infrared-absorption by the B-nitrogen aggregate in diamond. Philos Mag B 72(3):351-361. https://doi.org/10.1080/13642819508239089

Brozel MR, Evans T, Stephenson RF (1978) Partial dissociation of nitrogen aggregates in diamond by high temperature-high pressure treatments. Proc R Soc Lond A 361(1704):107-127. https://doi. org/10.1098/rspa.1978.0094

Bruley J (1992) Detection of nitrogen at $\{100\}$ platelets in a type IaA/B diamond. Philos Mag Lett 66(1):47-56. https://doi. org/10.1080/09500839208206012

Bruley J, Brown LM (1989) Quantitative electron energy-loss spectroscopy microanalysis of platelet and voidite defects in natural diamond. Philos Mag A 59(2):247-261. https://doi. org/10.1080/01418618908205057

Bulanova GP, Varshavsky AV, Kotegov VA (2005) A venture into the interior of natural diamond: genetic information and implications for the gem industry: part I: the main types of internal growth structures. J Gemmol 29(7/8):377

Bulanova GP, Speich L, Smith CB, Gaillou E, Kohn SC, Wibberley E, Chapman JG, Howell D, Davy AT (2018) The unique nature of Argyle fancy diamonds: internal structure, paragenesis and reasons for color. Econ Geol (in press)

Bursill LA (1983) Small and extended defect structures in gem-quality Type-I diamonds. Endeavour 7(2):70-77. https://doi.org/10.1016/ S0160-9327(83)80005-2

Clackson SG, Moore M, Walmsley JC, Woods GS (1990) The relationship between platelet size and the frequency of the $\mathrm{B}^{\prime}$ infraredabsorption peak in Type-Ia diamond. Philos Mag B 62(2):115128. https://doi.org/10.1080/13642819008226980
Clark CD, Davey ST (1984) One-phonon infrared-absorption in diamond. J Phys C 17(6):1127-1140. https://doi. org/10.1088/0022-3719/17/6/020

Davies G (1981) Decomposing the IR absorption-spectra of diamonds. Nature 290(5801):40-41. https://doi.org/10.1038/290040a0

Dyer HB, Raal FA, Dupreez L, Loubser JHN (1965) Optical absorption features associated with paramagnetic nitrogen in diamond. Philos Mag 11(112):763-774. https://doi.org/10.1080/14786 436508230081

Evans T, Kiflawi I, Luyten W, Vantendeloo G, Woods GS (1995) Conversion of platelets into dislocation loops and voidite formation in type IaB diamonds. Proc R Soc A 449(1936):295-313. https:// doi.org/10.1098/rspa.1995.0045

Fallon PJ, Brown LM, Barry JC, Bruley J (1995) Nitrogen determination and characterization in natural diamond platelets. Philos Mag A 72(1):21-37

Fisher D (2009) Brown diamonds and high pressure high temperature treatment. Lithos 112:619-624. https://doi.org/10.1016/j.litho s.2009.03.005

Goss JP, Coomer BJ, Jones R, Fall CJ, Briddon PR, Oberg S (2003) Extended defects in diamond: the interstitial platelet. Phys Rev B 67(16): https://doi.org/10.1103/PhysRevB.67.165208

Graham I, Burgess JL, Bryan D, Ravenscroft PJ, Thomas E, Doyle BJ, Hopkins R, Armstrong KA (1999) Exploration history and geology of the Diavik kimberlites, Lac de Gras, Northwest Territories, Canada. In: Proceedings of 7th International Kimberlite Conference, pp 262-279

Harte B (2010) Diamond formation in the deep mantle: the record of mineral inclusions and their distribution in relation to mantle dehydration zones. Mineral Mag 74(2):189-215. https://doi. org/10.1180/minmag.2010.074.2.189

Hirsch PB, Pirouz P, Barry JC (1986) Platelets, dislocation loops and voidites in diamond. Proc R Soc A 407(1833):239-258. https:// doi.org/10.1098/rspa.1986.0095

Howell D, O’Neill CJ, Grant KJ, Griffin WL, O'Reilly SY, Pearson NJ, Stern RA, Stachel T (2012) Platelet development in cuboid diamonds: insights from micro-FTIR mapping. Contrib Mineral Petrol 164(6):1011-1025. https://doi.org/10.1007/s0041 0-012-0786-9

Humble P (1982) The structure and mechanism of formation of platelets in natural Type Ia diamond. Proc R Soc A 381(1780):65-81. https://doi.org/10.1098/rspa.1982.0059

Hunt L, Stachel T, Morton R, Grutter H, Creaser RA (2009) The Carolina kimberlite, Brazil-insights into an unconventional diamond deposit. Lithos 112:843-851. https://doi.org/10.1016/j. lithos.2009.04.018

Kiflawi I, Bruley J (2000) The nitrogen aggregation sequence and the formation of voidites in diamond. Diam Relat Mater 9(1):87-93. https://doi.org/10.1016/S0925-9635(99)00265-4

Kiflawi I, Bruley J, Luyten W, Van Tendeloo G (1998) 'Natural' and 'man-made' platelets in type-Ia diamonds. Philos Mag B 78(3):299-314. https://doi.org/10.1080/13642819808205733

Kinny PD, Griffin BJ, Heaman LM, Brakhfogel FF, Spetsius ZV (1997) SHRIMP U-Pb ages of perovskite from Yakutian kimberlites. Geol Geofiz 38(1):91-99

Kohn SC, Speich L, Smith CB, Bulanova GP (2016) FTIR thermochronometry of natural diamonds: a closer look. Lithos 265:148-158. https://doi.org/10.1016/j.lithos.2016.09.021 the Nature of Diamonds and Their Use in Earth's Study

Lang AR (1964) A proposed structure for nitrogen impurity platelets in diamond. Proc Phys Soc Lond 84(5426):871-876

Luguet A, Jaques AL, Pearson DG, Smith CB, Bulanova GP, Roffey SL, Rayner MJ, Lorand JP (2009) An integrated petrological, geochemical and Re-Os isotope study of peridotite xenoliths from the Argyle lamproite, Western Australia and implications for 
cratonic diamond occurrences. Lithos 112:1096-1108. https://doi. org/10.1016/j.lithos.2009.05.022

Luyten W, Vantendeloo G, Fallon PJ, Woods GS (1994) Electronmicroscopy and energy-loss spectroscopy of voidites in pure type-IaB diamonds. Philos Mag A 69(4):767-778. https://doi. org/10.1080/01418619408242517

Melton GL, Stachel T, Stern RA, Carlson J, Harris JW (2013) Infrared spectral and carbon isotopic characteristics of micro- and macro-diamonds from the Panda kimberlite (Central Slave Craton, Canada). Lithos 177:110-119. https://doi.org/10.1016/j.litho s.2013.06.019

Mendelssohn MJ, Milledge HJ (1995) Geologically significant information from routine analysis of the mid-infrared spectra of diamonds. Int Geol Rev 37(2):95-110. https://doi.org/10.1080/00206 819509465395

Navon O, Wirth R, Schmidt C, Jablon BM, Schreiber A, Emmanuel $\mathrm{S}$ (2017) Solid molecular nitrogen $\left(\delta-\mathrm{N}_{2}\right)$ inclusions in Juina diamonds: exsolution at the base of the transition zone. Earth Planet Sci Lett 464:237-247. https://doi.org/10.1016/j.epsl.2017.01.035

Pearson DG, Shirey SB, Bulanova GP, Carlson RW, Milledge HJ (1999) Re-Os isotope measurements of single sulfide inclusions in a Siberian diamond and its nitrogen aggregation systematics. Geochim Cosmochim Acta 63(5):703-711. https://doi.org/10.1016/ S0016-7037(99)00042-3

Pidgeon R, Smith C, Fanning C (1989) Kimberlite and lamproite emplacement ages in Western Australia. Geol Soc Aust Spec Publ I(14):369-381

Richardson S (1986) Latter-day origin of diamond of eclogitic paragenesis. Nature 322:623-626

Rudloff-Grund J, Brenker FE, Marquardt K, Howell D, Schreiber A, O’Reilly SY, Griffin WL, Kaminsky FV (2016) Nitrogen nanoinclusions in milky diamonds from Juina area, Mato Grosso State, Brazil. Lithos 265:57-67. https://doi.org/10.1016/j.litho s.2016.09.022

Rudnick RL, Eldridge CS, Bulanova GP (1993) Diamond growth history from in situ measurement of $\mathrm{Pb}$ and $\mathrm{S}$ isotopic compositions of sulfide inclusions. Geology 21(1):13. https://doi. org/10.1130/0091-7613(1993)021<0013:DGHFIS>2.3.CO;2

Scott DW (2015) Multivariate density estimation: theory, practice, and visualization. John Wiley \& Sons, Hoboken

Shirey SB, Richardson SH (2011) Start of the Wilson cycle at 3 Ga shown by diamonds from subcontinental mantle. Science 333(6041):434-436. https://doi.org/10.1126/science.1206275

Smart KA, Chacko T, Stachel T, Muehlenbachs K, Stern RA, Heaman LM (2011) Diamond growth from oxidized carbon sources beneath the Northern Slave Craton, Canada: A $\delta 13 \mathrm{C}-\mathrm{N}$ study of eclogite-hosted diamonds from the Jericho kimberlite. Geochim Cosmochim Acta 75(20):6027-6047. https://doi.org/10.1016/j. gca.2011.07.028

Smith CB, Sims K, Chimuka L, Duffin A, Beard AD, Townend R (2004) Kimberlite metasomatism at Murowa and Sese pipes. Zimbabwe. Lithos 76(1-4):219-232. https://doi.org/10.1016/j. lithos.2004.03.009

Smith CB, Pearson DG, Bulanova GP, Beard AD, Carlson RW, Wittig N, Sims K, Chimuka L, Muchemwa E (2009) Extremely depleted lithospheric mantle and diamonds beneath the southern Zimbabwe Craton. Lithos 112:1120-1132. https://doi.org/10.1016/j.litho s.2009.05.013

Sobolev E, Lenskaya S, Lisoivan V (1969) Lamellar formations in the structure of natural diamonds. J Struct Chem 9(6):917-920 (translated from Zhurnal Strukturnoi Khimii, Vol. 9, No. 6, 1968, pp.10291033)
Speich L, Kohn SC, Wirth R, Bulanova GP, Smith CB (2017) The relationship between platelet size and the $\mathrm{B}^{\prime}$ infrared peak of natural diamonds revisited. Lithos 278281:419-426. https://doi. org/10.1016/j.lithos.2017.02.010

Stachel T, Harris JW (2008) The origin of cratonic diamonds-constraints from mineral inclusions. Ore Geol Rev 34(1-2):5-32. https://doi.org/10.1016/j.oregeorev.2007.05.002

Sumida N, Lang AR (1988) On the measurement of population-density and size of platelets in Type-Ia diamond and its implications for platelet structure models. Proc R Soc A 419(1857):235-257. https ://doi.org/10.1098/rspa.1988.0106

Taylor WR, Jaques AL, Ridd M (1990) Nitrogen-defect aggregation characteristics of some Australasian diamonds-time-temperature constraints on the source regions of pipe and alluvial diamonds. Amer Miner 75(11-12):1290-1310

Taylor WR, Canil D, Milledge HJ (1996) Kinetics of Ib to IaA nitrogen aggregation in diamond. Geochim Cosmochim Acta 60(23):47254733. https://doi.org/10.1016/S0016-7037(96)00302-X

Vantendeloo G, Luyten W, Woods GS (1990) Voidites in pure type IaB diamonds. Philos Mag Lett 61(6):343-348. https://doi. org/10.1080/09500839008206503

Vasilev EA, Sofroneev SV (2007) Zoning of diamonds from the Mir kimberlite pipe: results of Fourier-transformed infrared spectroscopy. Geol Ore Depos 49(8):784-791. https://doi.org/10.1134/ s 1075701507080120 (translated from Zapiski Rossiiskogo Mineralogicheskogo Obshchestva, 2007, Pt CXXXVI, No. 1, pp. 90101)

Vasilyev EA, Ivanov-Omskii VI, Bogush IN (2005) Interstitial carbon showing up in the absorption spectra of natural diamonds. Technic Phys 50(6):711-714. https://doi.org/10.1134/1.1947345 (translated from Zhurnal Tekhnicheskol Fiziki, 75(6), 2005, 3841)

Wiggers de Vries DF, Bulanova GP, De Corte K, Pearson DG, Craven JA, Davies GR (2013a) Micron-scale coupled carbon isotope and nitrogen abundance variations in diamonds: evidence for episodic diamond formation beneath the Siberian Craton. Geochim Cosmochim Acta 100:176-199. https://doi.org/10.1016/j. gca.2012.08.034

Wiggers de Vries DF, Pearson DG, Bulanova GP, Smelov AP, Pavlushin AD, Davies GR (2013b) Re-Os dating of sulphide inclusions zonally distributed in single Yakutian diamonds: evidence for multiple episodes of proterozoic formation and protracted timescales of diamond growth. Geochim Cosmochim Acta 120:363-394. https://doi.org/10.1016/j.gca.2013.06.035

Walter MJ, Kohn SC, Araujo D, Bulanova GP, Smith CB, Gaillou E, Wang J, Steele A, Shirey SB (2011) Deep mantle cycling of oceanic crust: evidence from diamonds and their mineral inclusions. Science 334(6052):54-57. https://doi.org/10.1126/scien ce. 1209300

Woods GS (1976) Electron-microscopy of giant platelets on cube planes in diamond. Phil Mag 34(6):993-1012. https://doi. org/10.1080/00318087608227724

Woods GS (1986) Platelets and the infrared-absorption of TypeIa diamonds. Proc R Soc A 407(1832):219-238. https://doi. org/10.1098/rspa.1986.0094

Woods GS, Kiflawi I, Kanda H, Evans T (1993) The effect of isotopic changes on the $\{001\}$ platelet infrared-absorption in diamond. Philos Mag B 67(5):651-658. https://doi.org/10.1080/13642 819308219314 